\title{
Electrochemical Corrosion of Nano-Structured Magnetron-Sputtered Coatings
}

\author{
Sebastian Calderon ${ }^{1,2, *}$, Cristiana F. Almeida Alves ${ }^{1,2}$, Noora K. Manninen ${ }^{3}$, \\ Albano Cavaleiro ${ }^{3}(\mathbb{D})$ and Sandra Carvalho 2,3 \\ 1 INL-International Iberian Nanotechnology Laboratory, Av. Mestre José Veiga s/n, 4715-330 Braga, Portugal; \\ cristiana.alves@inl.int \\ 2 CFUM-UP, Physics Department, University of Minho, Campus of Azurém, 4800-058 Guimarães, Portugal; \\ sandra.carvalho@fisica.uminho.pt \\ 3 SEG-CEMMPRE, Mechanical Engineering Department, University of Coimbra, 3030-788 Coimbra, Portugal; \\ noora.kristiina.m@gmail.com (N.K.M.); albano.cavaleiro@dem.uc.pt (A.C.) \\ * Correspondence: secave44@gmail.com
}

Received: 28 August 2019; Accepted: 8 October 2019; Published: 20 October 2019

\begin{abstract}
Magnetron sputtering has been employed for several decades to produce protective and multi-functional coatings, thanks to its versatility and ability to achieve homogeneous layers. Moreover, it is suitable for depositing coatings with very high melting points and that are thermodynamical unstable, which is difficult to accomplish by other techniques. Among these types of coating, transition metal $(\mathrm{Me})$ carbides/nitrides $(\mathrm{MeC} / \mathrm{N})$ and amorphous carbon $(\mathrm{a}-\mathrm{C})$ films are particularly interesting because of the possibility of tailoring their properties by selecting the correct amount of phase fractions, varying from pure $\mathrm{MeN}, \mathrm{MeC}, \mathrm{MeCN}$ to pure a-C phases. This complex phase mixture can be even enhanced by adding a fourth element such $\mathrm{Ag}, \mathrm{Pt}, \mathrm{W}, \mathrm{Ti}, \mathrm{Si}$, etc., allowing the production of materials with a large diversity of properties. The mixture of phases, resulting from the immiscibility of phases, allows increasing the number of applications, since each phase can contribute with a specific property such as hardness, self-lubrication, antibacterial ability, to create a multifunctional material. However, the existence of different phases, their fractions variation, the type of transition metal and/or alloying element, can drastically alter the global electrochemical behaviour of these films, with a strong impact on their stability. Consequently, it is imperative to understand how the main features intrinsic to the production process, as well as induced by $M e$ and/or the alloying element, influence the characteristics and properties of the coatings and how these affect their electrochemical behaviour. Therefore, this review will focus on the fundamental aspects of the electrochemical behaviour of magnetron-sputtered films as well as of the substrate/film assembly. Special emphasis will be given to the influence of simulated body fluids on the electrochemical behaviour of coatings.
\end{abstract}

Keywords: electrochemical corrosion; magnetron sputtering; nitrides; carbides

\section{Introduction}

Magnetron sputtering (MS) is a very versatile technique that allows the production of a variety of coatings with a large range of compositions, structures, and morphologies. Being an environment-friendly process, magnetron sputtering can replace, with advantage, polluting coating techniques such as electroplating, anodization, or chemical vapour deposition.

Surface modification with MS coatings is a well-established approach, which allows to improve the lifetime of bulk materials and to add new functionalities. Coatings are usually produced to protect base materials against wear or corrosion or to add functional properties to a system. For electrochemical 
corrosion protection, ceramic coatings have been used to fulfil these requirements. Within the vast family of ceramic materials, transition metal $(\mathrm{Me})$ nitrides, carbides, and carbonitrides have been widely studied because of their potential multifunctionality, providing the system with good mechanical performance as well as chemical inertness. Presently, different protective and multifunctional coatings based on $\mathrm{MeN}$ and $\mathrm{MeCN}$ as well as carbon-based coatings such as diamond-like carbon (DLC), amorphous carbon (a-C), etc., are found in the market and used for different applications in the automotive, aerospace, food packaging, or biomedical industries. This review will be focused on the electrochemical behaviour of MS-deposited coatings within the families of transition metal nitrides $(\mathrm{MeN})$, carbides $(\mathrm{MeC})$, carbonitrides $(\mathrm{MeCN})$, and carbon-based (C-based) films.

Although $\mathrm{MeCN}$ and carbon-based materials are chemically inert, when deposited by magnetron sputtering, their stability decreases, since they are highly prone to form complex sub-stoichiometric structures with different intrinsic properties. The crystalline arrangement and morphology of the coatings change depending on film stoichiometry and on the deposition conditions of the process. Thus, despite their general chemical inertness, these coatings fail because of the changes in their properties upon sputtering. These changes include (i) a higher ability of the sputtered coatings to form complex structures and phases arrangements, in comparison to the bulk materials; (ii) different morphologies/microstructures from those of the bulk materials, depending on the deposition conditions; (iii) appearance of defects determined by the coating thickness; (iv) presence of the substrate with, typically, a more active electrochemical behaviour.

Besides, arc discharges, dust, and micro-impurities on the surface of the substrates lead to the formation of macro defects, known as pinholes and droplets [1]. The presence of such defects exposes the substrate to the electrolyte, activating several electrochemical reactions that decrease the coating corrosion protection and induce metal ion release from the substrate, causing film delamination and wear debris [2]. For those reasons, localized corrosion is one of the most critical forms of corrosion for magnetron-sputtered coatings. The corrosion is potentiated by the difference in reduction potential between the coatings and the substrate, creating galvanic corrosion in the pits, as will be later detailed. In addition, the dissimilar ion concentration in these regions potentiates the growth of such localized corrosion. In fact, even in substrates with generalized corrosion, the films seem to induce pitting corrosion [3]. Then, it is possible to control the defects and the morphology of the coatings to avoid the formation of pits, which is one of the challenges encountered when designing magnetron-sputtered films with corrosion-resistant properties.

Among the most reported application of $\mathrm{MeN}, \mathrm{MeCN}$, and C-based films, which require anticorrosion properties there are: the enhancement of mechanical steel parts [3,4], the improvement of magnesium alloys [5,6] and aluminum alloys [7], the protection of magnetic materials [8,9], and the improvement of biomedical devices [3,10-13], with the the last one being one of the key applications for the analysis of electrochemical performance. A detailed summary of some of the electrochemical studies developed on coatings deposited by magnetron sputtering, which emphasize the substrate, type of coating, electrolyte, and tests utilized, can be found in the Supplementary Information (Table S1).

\section{Chemical and Morphological Properties Influencing the Electrochemical Properties of Magnetron-Sputtered Films}

The chemical and morphological characteristics are the key parameters to control the electrochemical behaviour of coatings and the main focus of study when analyzing the electrochemical performance of coatings.

The intrinsic chemical inertness of these materials largely depends on the environment and on the type of transition metal elements used. However, it is generally accepted that these compounds are chemically resistant due to their ceramic nature. The electrochemical studies of the bulk phases of these materials are scarce, but general behaviours can be elucidated on the basis of the chemistry of such materials. For nitrides, for instance, two families of compounds have been mainly used in magnetron sputtering. These are interstitial nitrides, i.e., transition metal from groups IIIB, IVB, and VB, which are 
chemically inert and are hydrolyzed, at very low rates, only in the presence of an acid medium [14]. The second group of nitrides deposited by magnetron sputtering is that of covalent nitrides, such as $\mathrm{BN}, \mathrm{Si}_{3} \mathrm{~N}_{4}$ and AlN. These nitrides are supposed to undergo hydrolysis forming hydroxides [14], which may lead to passivation due to the transformation of the hydroxide to oxides, such in AlN [15]. Transition metal carbides are also chemically inert, present low reactivity in several environments, and show degradation only in concentrated acids or bases and in the presence of oxidizing agents [16].

Thus, for pure stoichiometric ceramic phases, the intrinsic behaviour of the material determines the reactivity of the coatings. However, since the composition of these magnetron-sputtered films can largely vary, slight deviations from the stoichiometric composition of the ceramic phase produce changes in the electrochemical response, as will be further explored in the following section. The effects of the morphology and defects of the films mainly determine the amount of electrolyte that contacts the substrate, defining the diffusion paths and the area of the films and substrate in contact with the electrolyte and also affecting the electrochemical corrosion response of the system.

All these features can be modified by simply altering the production conditions during magnetron sputtering deposition. In the following sections, we attempt to summarize the effects of these changes on the electrochemical response of the system substrate/coating/electrolyte.

\subsection{Chemical Characteristics Affecting the Electrochemical Corrosion of the Coatings}

Different compositions of the coatings influence the electrochemical behaviour of the coatings. Depending on their stoichiometry and the surrounding environment, the films may be classified into (i) intrinsically inert, (ii) passive coatings, and (iii) active coatings. The intrinsically inert films are mainly composed of pure phases such as diamond-like carbon films in saline solutions, which do not react with the electrolyte, and thus, their electrochemical response is due to the interaction between the electrolyte and the substrate. The passive coatings, on the other hand, possess elements that form very stable thin passive layers on the surface of the materials. For instance, coatings with transition metal in $\mathrm{MeN}$, $\mathrm{MeCN}$, or even C-based films with embedded Me usually auto-passivate in different types of solutions, providing chemical stability. $\mathrm{Cr}, \mathrm{Ti}, \mathrm{Zr}$, and $\mathrm{Nb}$, among other metals, create these types of passive layers known to protect again corrosion. In $\mathrm{CrN}$ films, the passive layer has been reported to be mainly formed by $\mathrm{Cr}_{2} \mathrm{O}_{3}$ [17], but some authors state that it may also contain $\mathrm{Cr}(\mathrm{OH})_{3}$ and $\mathrm{CrO}_{3}$ [17]. TiN [18], $\mathrm{ZrN} \mathrm{[19],} \mathrm{and} \mathrm{ZrCN}$ have been reported to form graded passive layers containing the oxynitrides $\mathrm{MeON}$ and $\mathrm{MeO}_{x}$. Also niobium passivates by forming $\mathrm{Nb}_{2} \mathrm{O}_{5}$, which protects against corrosion [20]. Finally, active coatings interact with the electrolyte, not only working as a protective layer but also providing it with additional properties. In this group, $\mathrm{MeCN}$ and a-C films are incorporated with a metallic element $(\mathrm{Cu}, \mathrm{Ag}$, Ti, etc.) which is released in the environment, thus inducing a controlled reaction and specific properties, such as antibacterial, self-lubricant properties, etc.

However, in order to better differentiate the effect of the coatings composition on the electrochemical performance, this analysis will consider two main groups, nitrides and carbonitrides on one hand, and carbon-based films on the other, taking into account that similar tendencies can be underlined within these groups for different compositions.

\subsubsection{Nitrides and Carbonitrides $(\mathrm{MeN}$ and $\mathrm{MeCN})$}

Transition metal (carbo)nitrides can be deposited in a large variety of conditions that allow the production of sub-stoichiometric and stoichiometric films, in which the amounts of carbon and nitrogen are controlled by the amount of reactive gas(es) $\left(\mathrm{N}_{2}\right.$ and $\left.\mathrm{C}_{x} \mathrm{H}_{y}\right)$ delivered to the sputtering chamber or by applying different power/current densities to the transition metal target. When the films possess sub-stoichiometric composition $\left(\mathrm{MeN}_{x}\right.$ with $\left.x<1\right)$, the excess of $M e$ promotes the existence of two different phases, which in turns will behave differently electrochemically, because of the tendency of $M e$ to passivate or react, as previously explained, in contrast to inert $M e \mathrm{~N}_{x}$. For example, Pedrosa et al. [21] showed that free titanium in Ti-rich TiN samples led to lower corrosion potentials and higher passivation currents due to the active behaviour of Ti. 
Nonetheless, it is difficult to separate the morphological and structural effects from the composition of the films, since changes in the composition are usually attained by altering the deposition conditions of the coatings, which, in turn, promotes variations in the morphology and structure, modifying the electrochemical performance of the coatings. For instance, AlN [22] and $\mathrm{CrN}$ [23] studies demonstrated that the increase of the nitrogen flux during film growth can decrease the current density in the electrolyte as a result of the densification of the coating, also reducing the pitting potential of AlN [22]. On the contrary, TiN films with denser morphologies are produced with low percentages of $\mathrm{N}$, while, for near-stoichiometric films, the columnar structure increases the area in contact with the electrolyte, which reduces the corrosion resistance properties of the films, because of the capacity of the electrolyte to permeate the films [24-26].

Effect of Metals Incorporation on $\mathrm{Me}(\mathrm{C}) \mathrm{N}$ Electrochemical Response

Some researchers alter the composition of the coatings, aiming to improve their protection capabilities or to add new functionalities, which in turns modify the electrochemical behaviour of the coatings. By adding elements such as $\mathrm{Al}$ [27-29], $\mathrm{Mg}$ [30], $\mathrm{Hf}$ [31], $\mathrm{Zr}$ [31], $\mathrm{Ag}$ [32,33], W [34], the columnar growth of the coatings is altered, creating more compact morphologies, as schematized in Figure 1. This reduces the porosity of the coatings and prevents the penetration of the electrolyte. Additionally, these elements react with the electrolyte forming corrosion products that remain trapped in the coatings, blocking the diffusion paths of the electrolyte and avoiding the contact with the substrate. TiAlN and CrAlN coatings, for instance, have been reported to present better corrosion resistance as compared to TiN and $\mathrm{CrN}$ coatings, due to the formation of an $\mathrm{Al}_{2} \mathrm{O}_{3}$ layer that passivates the films surface and to the modification of the columnar morphology of the coatings, which reduces the porosity [27,29,35]. Fenker et al. [30] have also demonstrated that the addition of Mg in TiN films reduces the appearance of pits to a greater extent than other approaches such as the addition of hydrocarbons, the creation of multilayer systems, and etching processes. In fact, $\mathrm{Mg}$ can lead to a decrease in the potential difference between the coating and the substrate, avoiding galvanic corrosion.

Particularly, when silver is incorporated in large quantities, the polarization resistance is reduced as silver amount increases in $\mathrm{TiN}$ [33] and $\mathrm{ZrCN}$ [36,37], as a result of the higher electroctrochemical activity of silver. Moreover, the addition of $\mathrm{Si}$ to $\mathrm{Me}-\mathrm{Si}-\mathrm{N}$ films can change and improve some properties of the coatings, such as surface hardness and corrosion resistance [38]. Cui et al. [38] proved that $\mathrm{Si}$ addition in low amounts increased the corrosion resistance of films. For a Si content around 8 at.\%, films achieved the best corrosion resistance. However, a further increase of $\mathrm{Si}$ amount deteriorated the passive layer formed on the coatings' surface, decreasing their corrosion resistance. 


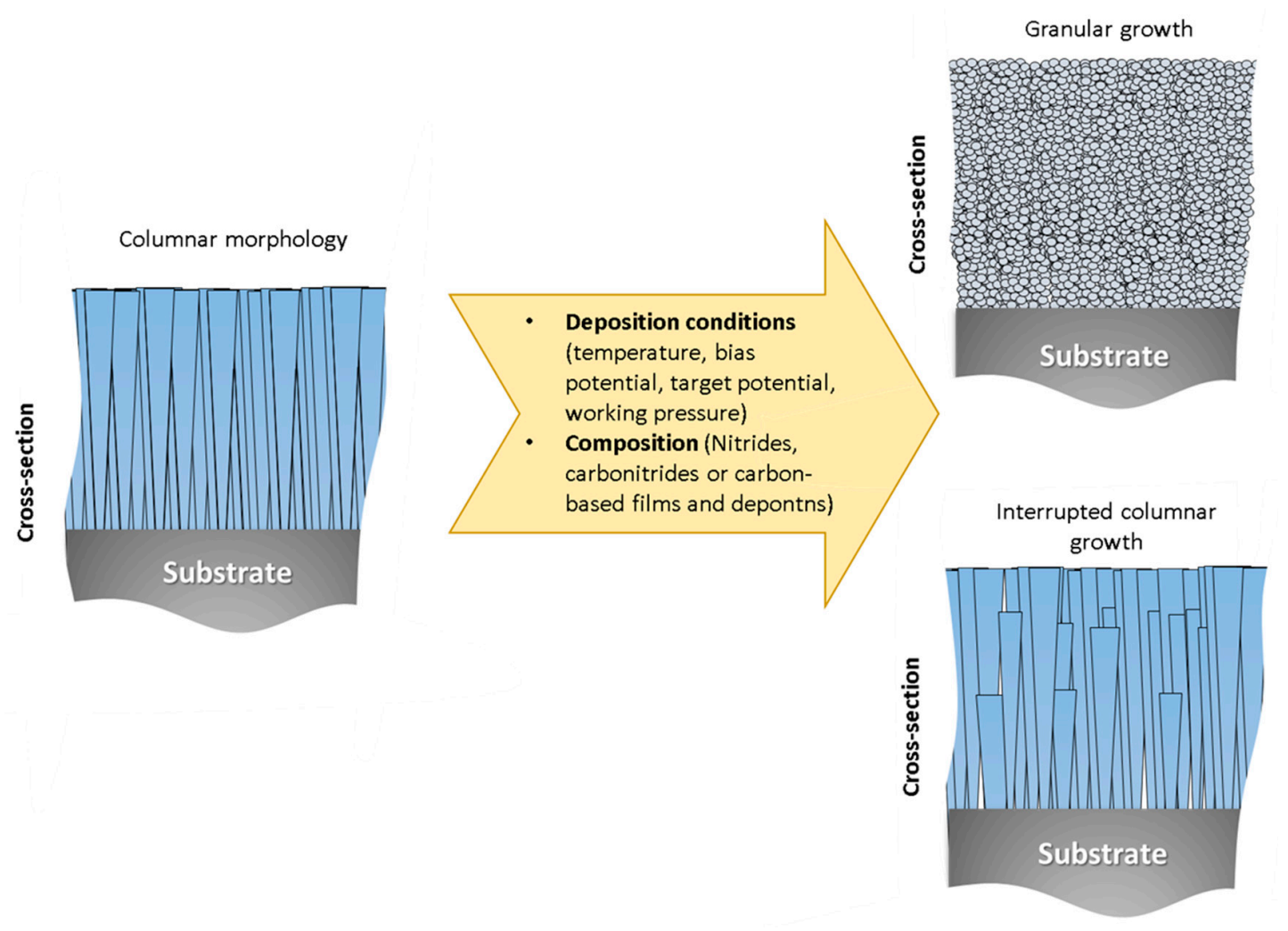

Figure 1. Morphological changes due to processing and/or compositional changes.

More complex systems have been proposed to create a nanocomposite that modifies the morphology of the coatings and provides a variety of phases. Amorphous phases are usually used in order to create denser morphologies. $\mathrm{Si}_{3} \mathrm{~N}_{4}$, for instance, has been incorporated into TiN coatings to improve the corrosion resistance of the coatings [39], also providing additional charge transfer resistance due to its dielectric character.

Some reports have demonstrated that the incorporation of $C$ into nitrides to form carbonitrides such as TiCN [40] and BCN $[4,41]$ films transforms the material in less electrochemically active films, improving their corrosion resistance. This behaviour results from the increase of the non-metal/metal ratio, which leads to the formation of an a-C phase. The formation of an a-C phase is responsible for the densification of the microstructure as well as for the decrease in porosity and, hence, for the decrease of the penetration paths of corrosive media, which enhances the corrosion resistance. However, special care should be taken with these materials, since carbonitrides can also create nanocomposite films by introducing large amounts of carbon into the films. The excess of carbon generates a competition between $\mathrm{MeCN}$ and a-C and creates regions in which the mixture of phases can act as cathode and anode in the reaction and accelerate the anodic process [42].

\subsubsection{Carbon-Based Films (a-C and DLC)}

Nowadays, C-based coatings are one of the most valuable engineering materials. Carbon is one of the most common elements in the earth and it can be found in nature in different allotropic forms, such as graphite or diamond. DLC coatings have a large variety of physical properties mainly related to the different hybridization states present in carbon coatings $\left(s p^{1}, s p^{2}\right.$, and $\left.s p^{3}\right)$, where the presence of $s p^{3}$ bonds, characteristic of diamond, leads to high hardness and chemical and electrochemical inertness, while the presence of $s p^{2}$ bonds, characteristic of graphite, allows obtaining low friction coefficients and high electrical conductivity, just to mention a few characteristics. The different forms of DLC coatings are displayed in a ternary phase diagram, developed by Jacob and Moller, where the amounts of $s p^{3}$ and $s p^{2}$ bonds and hydrogen determine the type of structure [43]. 
The main compositional characteristic of carbon films influencing the electrochemical performance of coatings is the ratio between $s p^{2}$ and $s p^{3}$ carbon bonds, which can be modified using parameters such as reactive gases $\left(\mathrm{C}_{x} \mathrm{H}_{y}\right)$ and power in the $\mathrm{C}$ target. Some studies highlight that the increment of $s p^{2}$ with respect to $s p^{3}$ bonds may lead to an easy dissolution of the films, due to the lower amount of cross-linked bonds in the structure [44-46]. In the case of a-C:H, it has been also pointed out that the reduction of the electrochemical conductivity may offer more protection, increasing the charge transfer resistance and decreasing the galvanic corrosion between the substrate and the films $[9,47,48]$. Additionally, it is also mentioned that hydrogenated coatings showed denser morphologies and less superficial defects, which prevented the electrolyte to penetrate through the coating, thus increasing corrosion resistance $[9,49]$.

\section{Effect of Metals on Carbon-Based Films Electrochemical Response}

In the case of carbon-based films (DLC and a-C coatings), the use of metals is mainly proposed for enhancing the adhesion of the DLC coatings to the substrates, reducing the residual stress of the coatings. Contrary to the nitrides, in carbon-based films, the incorporation of Ti [12], $\mathrm{Cr}$ [12,50], Ni [44], $\mathrm{Ag}$ [51], among other metals, can: (i) Increase the electrochemical activity of the coatings, depending on the amount incorporated, since these metals can work as active sites on the films surface, being potentiated by the galvanic corrosion between $C$ and the metals, as schematized in Figure 2, (ii) Promote changes in the ratio between the $s p^{2}$ and $s p^{3}$ bonds, inducing a reduction or an increment in the charge transfer resistance [12,51], depending on the metal used, (iii) Produce changes in the morphology of the coatings. This last event is highly dependent on the used metal and its ability to form carbides.

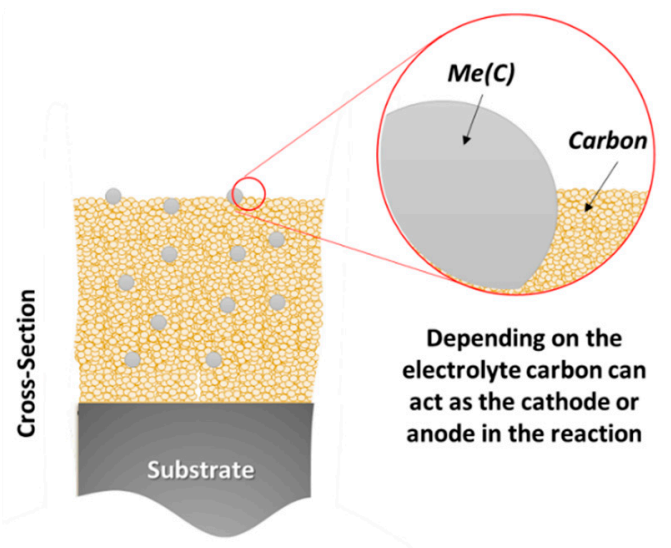

Figure 2. Schematic galvanic couples formed between carbon and metals embedded in the matrix.

The amount of metallic species incorporated into the carbon-based films seems to be the key parameter influencing the electrochemical performance of the coatings. Hong et al. [52] proposed to deposit a-C films with less than $3.1 \mathrm{at} . \%$ of $\mathrm{Ti}$, since they are stably passive in Hanks' solution. However, when Ti content increased up to 15.2 at.\%, the a-C film exhibited dynamic passivation and possible deoxidization due to the low $s p^{3}$ volume fraction, being susceptible to crevice pitting corrosion. Wang et al. [12] compared $\mathrm{Ti}$ and $\mathrm{Cr}$ incorporation; both elements revealed an improved corrosion performance due to the formation of $\mathrm{Ti}$ and $\mathrm{Cr}$ oxides onto the surface and to the blocking behaviour that prevented the penetration of the electrolyte. However, at a certain point, the increase of Ti amount $\left(\approx 20\right.$ at.\%) weakened the barrier effect as a consequence of the increase of the $s p^{2} / s p^{3}$ ratio as well as of conductivity. Yet, increasing $\mathrm{Cr}$ amount continued to increase the corrosion resistance of a-C coatings through either $\mathrm{Cr}$ passivation or $s p^{2} / s p^{3}$ ratio decrease. Liu et al. [53] showed that for low amounts of $\mathrm{Ti}\left(2.7\right.$ at.\%), compressive stress in a- $\mathrm{CN}_{x}: \mathrm{Ti}$ coatings was released due to the low $s p^{3}$ volume fraction, enhancing the adhesion strength between the film and the substrate, reducing the number of defects, and subsequently blocking the electrolyte. However, further increasing the Ti content into the a- $\mathrm{CN}_{x}$ 
matrix, increased the $s p^{2}$ volume fraction, which destroyed the nanocomposite compact structure and thus boosted pitting corrosion.

Si has been demonstrated to improve the corrosion resistance $[48,54]$ by reducing the internal stress, which prevented the catastrophic failure of the films [54]. PtRu aggregates, on the other hand, have also been incorporated into carbon films, blocking the ion diffusion paths and increasing the transfer resistance of the films [55]. The authors suggested that $\mathrm{Pt}$ and $\mathrm{Ru}$ incorporation improves corrosion resistance by cathodic protection, avoiding pitting corrosion without compromising adhesion strength, thanks to the nobler electrochemical character of $\mathrm{Pt}$ and $\mathrm{Ru}$ when compared with $\mathrm{C}$. The incorporation of $\mathrm{N}$ to DLC coatings reduced the electrical resistivity, inducing galvanic corrosion between the films and the substrate and thus deteriorating the corrosion resistance of the system $[45,55,56]$. Additionally, it has been shown that $\mathrm{N}$ improved the adhesion strength of the films but increased $s p^{2}$ bonds [57]. With the increase of $s p^{2}$ bonds and subsequent decrease of $s p^{3}$ bonds, the cross-linked structure was degraded, which caused a decrease of its density and an increase of its porosity. With the increase of the coating's porosity, the diffusion paths through the coating to the substrate interface increase, causing the system deterioration.

\subsection{Morphological Characteristics Effect on the Electrochemical Corrosion Performance}

For pure capacitive films, which play only a protective role, the electrochemical response should reflect the behaviour of a capacitor. However, the electrochemical response of magnetron-sputtered films is usually far from that of a perfect capacitor and it is mainly due to the interaction of the electrolyte and the substrate throughout the defects and morphological features of the films. In such cases, pinholes, drops, columnar growth, among others, can allow the electrolyte to contact the substrate and accelerate a localized corrosion of the coatings due to the potential difference between the films and the substrate, as schematized in Figure 3. This section focuses on the influence of coating's growth, thickness, porosity, and defects on the corrosion behaviour, which governs the permeability of the electrolyte through a coating.

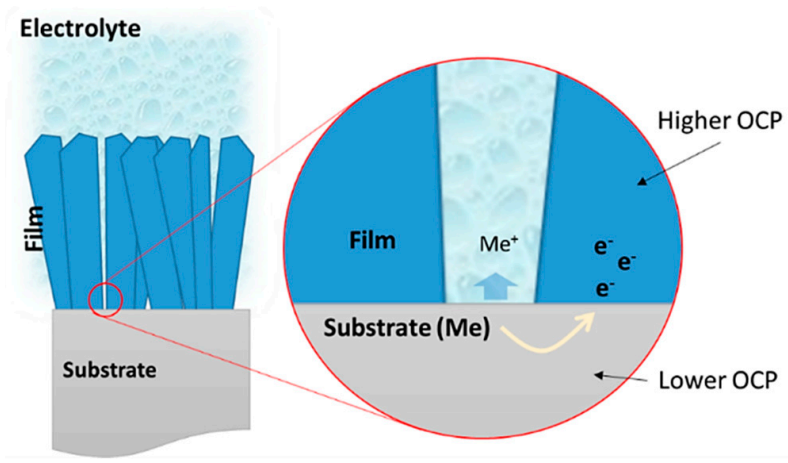

Figure 3. Scheme of galvanic corrosion through the defect promoted by the higher open circuit potential (OCP) of the film compared to that of the substrate.

\subsubsection{Influence of Coating's Growth}

The columnar growth of magnetron-sputtered films has been known for a long time, and several models have been developed to describe, in general, the growth of sputtered film. This morphology can be modified by changing the deposition parameters, including power density, pressure, and temperature of the deposition, and by applying bias voltage to the substrates [7,58,59], modifying the stoichiometry of the coatings (as previously discussed), or even altering their architecture. The morphology is a predominant feature that alters the electrochemical response of the coatings, since it controls the permeability of the electrolyte, allowing it to contact the substrate and increasing the dissolution rate of the system. Lui et at. [60], for example, presented a complete comparison between TiN and $\mathrm{CrN}$, showing that more equiaxed crystallites in $\mathrm{CrN}$ coatings could restrict the diffusion of oxygen (or of 
an electrolyte species) to the substrate, while columnar crystallites in TiN provided a straight path for that diffusion, explaining the better corrosion resistance of $\mathrm{CrN}$ compared to TiN. Such results demonstrate that, despite the intrinsic electrochemical behaviour of the coatings, the morphology of the coatings plays a dominant role in the corrosion protection of the substrate. Therefore, to properly create a protective coating, not only an inert material must be selected, but also the best conditions to produce dense coatings, free of defects, must be chosen. This methodology is still being developed within magnetron sputtering, since, despite the great efforts made to remove the defects in films, these defetcs are still one of the main causes of failure. The principal effect of morphological growth can be clearly deduced from Franco et al. [4], who demonstrated that TiN films produced by MS may present lower corrosion resistance than plasma-nitrided Ti coatings, which possess a more granular, compact morphology compared to MS TiN, characterized by a typical columnar growth.

$\mathrm{MeCN}$ and C-based films typically present denser morphologies when compared to films based on transition metal nitrides, with lower porosity and improvement of the corrosion resistance $[11,61]$. For example, Madaoui et at. [61] studied the corrosion resistance of TiN and TiCN coatings, finding that $\mathrm{TiCN}$ showed better corrosion resistance compared to TiN due to its smoother surface and more compact morphology [61]. Nonetheless, it must be taken into consideration that the electrochemical corrosion behaviour of $\mathrm{MeCN}$ largely depends on the stoichiometry of the compound. An excess of carbon in the carbonitride may create a larger number of interfaces between the $\mathrm{MeN}(\mathrm{C})$ and carbon phases, which can induce higher electrochemical porosity of the coatings [36,37].

\subsubsection{Influence of Pores}

Porosity in magnetron sputtering is usually observed in columnar or granular films or at the interfaces between different phases growing in competition, where the boundary regions act as microor nanopores that allow the diffusion of the electrolyte species and accelerate the substrate attack. As the electrolyte penetrates the films throughout the pores, two scenarios can be foreseen, depending on the nature of the films: (i) The electrolyte does not react with the film and penetrates to the substrate or (ii) The electrolyte reacts with the coating, passivating the surface and blocking the pores with the corrosion products [20]. Electrochemical porosity is usually calculated by comparing the polarization resistance of the bare substrate and that of the coated substrate $[10,11,27,62-66]$, making use of the empirical equation deduced by Elsener et al. [67] (see Equation (1)):

$$
P=\frac{R_{s}}{R_{p}} 10^{\left(-\frac{|\Delta E|}{\beta_{\mathrm{a}}}\right)}
$$

where $P$ is the total coating porosity, $R_{s}$ is the polarization resistance of the bare substrate, $R_{p}$ is the polarization resistance of the coating, $\beta_{\mathrm{a}}$ is the anodic Tafel slope of the bare stainless steel, and $\Delta E$ is the difference in corrosion potential between the coated and the bare substrate. However, special care must be taken when using this approach, since it is valid for pure capacitive/protective films, for which the electrochemical signal is mainly due to the interaction between the substrate and the electrolyte, which is determined by the porosity of the films.

\subsubsection{Defects in Magnetron-Sputtered Coatings}

As mentioned before, several studies have suggested that typically microscopic defects arising from sputtering techniques expose the substrate to corrosive media, deteriorating the corrosion protection of the coatings. The defects are perturbations in the growth of the coatings, which create macropores or impurities in the films. These defects are usually formed by arc discharges during the sputtering process or dust and micro-impurities present in the substrate surface, or are pre-existent defects, such as cracks or rough surfaces $[1,68]$.

These defects can be of several types, depending on their origin, and are divided in (i) flakes; (ii) open voids, (iii) cone-like defects, (iv) pinholes, (v) droplets [1,68]. Macro defects are mainly attributed to the substrate pre-treatment or to dust particles in the deposition chamber, which promote 
the formation of inclusions. Micro and sub-micro defects are generated during ion etching and deposition and can have different origins, such as microparticle flaking generated during the deposition process. Another source of defects is the occurrence of arc during the etching and deposition steps. Some studies have evaluated the influence of the processing parameters on the densitiy of coatings' defect [1], namely, the influence of deposition time, deposition rate, substrate type, and substrate location in the deposition chamber. They reported that the defect density is independent on the coating's thickness, whereas the increase in the deposition time enhances the defects density. The results pointed out by these authors suggest that the substrate cleaning procedure and chamber cleaning state have a strong influence on defects formation. Several indications for minimizing these defects are provided by the authors, namely: (i) Fast drying of the substrates after rinsing in de-ionized water, with hot air in order to avoid the sticking of dust particles, (ii) Periodical cleaning of all vacuum components, in order to avoid the transfer of delaminated coating to the substrate promoted by, e.g., thermal stress, (iii) Performing low venting and pumpdown to reduce turbulent airflow which promotes the sticking of dust particles.

The effects of these defects on the electrochemical performance depend on the type of defects, hampering a quick correlation between the evaluation of the distribution of defects, usually performed by optical images, and the corrosion resistance of the coatings. For instance, when the defects penetrate completely the films (Figure 4a), they produce fast diffusion paths that allow the electrolyte to contact the substrate, increasing the electrochemical activity. In other cases (Figure $4 \mathrm{~b}$ ), their effect is not critical for the corrosion of the substrate but only modifies the area of the films in contact with the electrolyte, and thus, the electrochemical response remains the same.

a)

b)

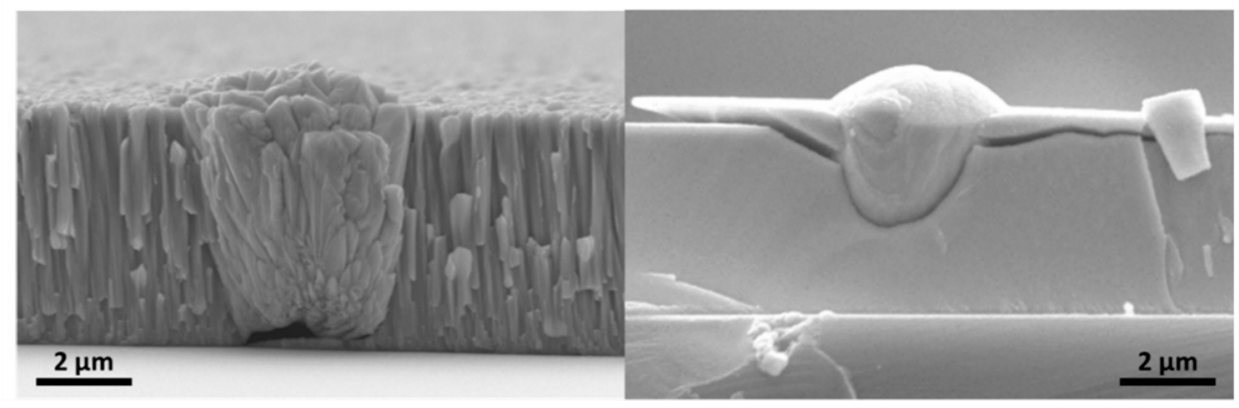

Figure 4. Magnetrons sputtering coatings cross-sectional images showing (a) throughout defect, (b) interrupted defect.

The majority of the studies demonstrate and highlight the importance of the micro-defects of the coatings as one of the most relevant characteristics influencing the electrochemical performance of the coatings as protective films. In fact, catastrophic failure of the coatings $[5,20,69]$ and localized corrosion are the most reported consequences due to the penetration of an electrolyte through the defects, which corrodes the substrate $[6,34]$. The size of the defects may determine the type of failure in the coatings, since large pores (pinholes) can easily transport the corrosion products, which allows the detachment of the films and produces catastrophic failure due to the increase in local stress [70], while small defects can be easily blocked by the corrosion products, and then their effect is diminished, as schematized in Figure 5. 

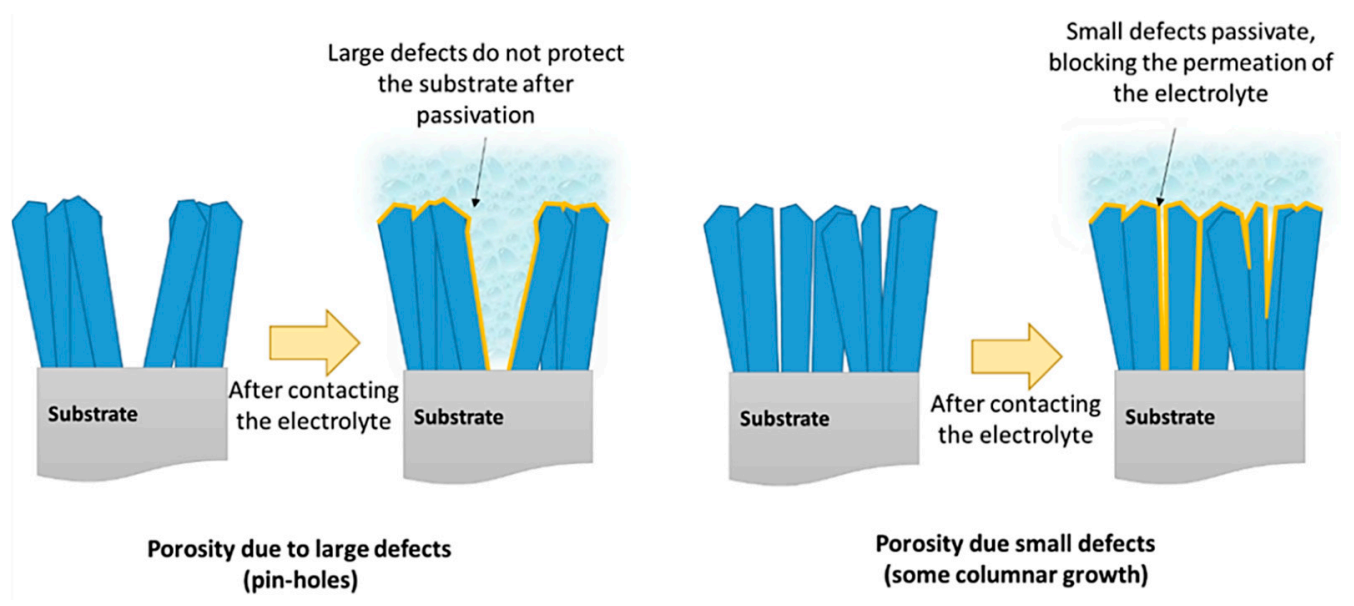

Figure 5. Passivation of pores and defects.

\subsubsection{Multilayered Systems}

Another widely studied possible solution to interrupt the creation of defects as well as block the diffusion paths through the coating is the deposition of multilayered systems. Several architectures have been suggested, among which those schematized in Figure 6, which are the most used. The multilayered approaches promote re-nucleation in the coatings, create a large number of interfaces, and reduce the porosity, hindering the propagation of micro-cracks and avoiding pinholes and pore continuity [71,72]. This methodology improves the polarization resistance of the coatings and reduces their electrochemical porosity $[8,64,65,71-74]$, clearly associated with a reduction of the permeation of the coatings.

a)

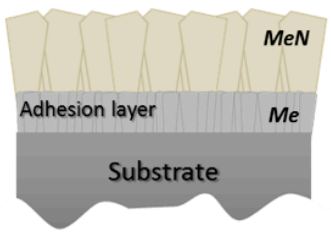

b)

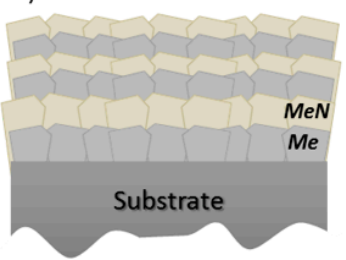

c)

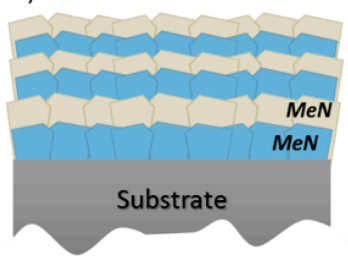

d)

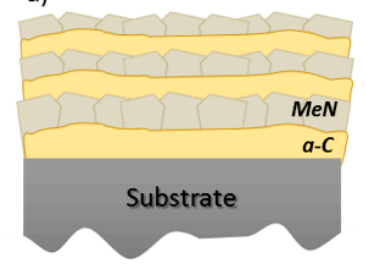

Figure 6. Schematic representation of multilayered systems used to prevent corrosion. (a) Metal/nitride bilayer, (b) metal/nitride multilayer, (c) dissimilar metal/nitride multilayer, and (d) carbon-based/nitride multilayer.

The simplest multilayer system is a bilayer system, consisting of an interlayer (usually metallic) to increase the adhesion between the substrate and the protective coating, which creates an additional interface and modifies the morphology of the coating. This approach has shown to be effective to improve the corrosion resistance and reduce spilling in $\mathrm{ZrN}$ coatings [69]. A similar behaviour has been reported for $\mathrm{Nb} / \mathrm{CrN}$ [75], $\mathrm{Ni} / \mathrm{TiAlN}$ [66], $\mathrm{Al} / \mathrm{AlN}$ [76], where the metallic interlayer enhances the corrosion resistance of the coatings.

More complex multilayer systems are based on the combination of $\mathrm{Me} / \mathrm{MeN}[71,77]$, of two $\mathrm{MeNs}$, i.e., $\mathrm{CrN} / \mathrm{NbN}$ [30,75], TiN/NbN [72], $\mathrm{Cr} / \mathrm{CrN} / \mathrm{CrAlN}$ [78], TiAlN/CrN [29,66], TiN/TiAlN [27], or of $\mathrm{MeN} / \mathrm{a}-\mathrm{C}$, e.g., CrN/a-C and TiN/a-C [48]. In these systems, the period of the layers is one of the parameters that most dramatically affect the results, since when reducing the period (thickness of the bilayers), the number of interfaces increases, restricting the diffusion path, slowing the diffusion of the electrolyte, enhancing the corrosion resistance of the coatings [72,73] and reducing the localized corrosion observed on the surface of the materials [71,72]. Flores and co-authors [71], for instance, proved that $\mathrm{Ti} / \mathrm{TiN}$ multilayers improved the corrosion performance of SS 304 steel, proportionally to the number of layers deposited, performing better than TiN monolayers,. Additionally, Fenker et al. [30] pointed out that in a multilayered system, the ending layer largely influences the corrosion behaviour 
of the coatings, due to the intrinsic behaviour of the material. For instance, better corrosion resistance is observed when $\mathrm{NbN}$ is the topmost layer when compared to $\mathrm{CrN}$ in the $\mathrm{CrN} / \mathrm{NbN}$ system.

\section{Electrochemical Corrosion Behaviour of $\mathrm{MeN}, \mathrm{MeCN}$, and a-C-Based Coatings in Biomedical Devices}

The human body represents a very complex and demanding system; thus, the materials coming in contact with it must be carefully selected. The requirements of each biomaterial are strongly determined by their final application. For instance, ureteral stents require high resistance to encrustations, dental implants require good osseointegration ability, cardiovascular biomaterials must be hemocompatible, and joint prosthesis must resist wear and high loads. Besides the highly specific properties related to each type of medical device, one common requirement is necessary: the ability to reduce the release of metal ions which can interact with the human body and produce adverse reactions, leading to biomaterial's rejection. In other words, the ability to protect metallic implants from corrosion is a demanding requirement in any indwelling biomedical device. Despite the issues related to the corrosion of metallic biomaterials, this class of materials has an important role in the biomedical field, and several materials have been proposed for use in biomedical devices, namely, SS316L [79], cobalt-chromium-molybdenum alloys (Co-Cr-Mo) [80], nitinol (NiTi) memory-shape alloys [81], commercially pure titanium grade 2 (CP Ti Grade 2) [82,83] and titanium-6aluminium-4vanadium alloys (Ti6Al4V, Ti Grade 5) [84-86]. SS316L is a good biomaterial for bone replacement, commonly used in trauma surgery. This material has good mechanical properties and is easily produced at a very low cost [80]; however, generally, stainless steels are subject to localized corrosion, such as pitting corrosion, in long-term applications due to the aggressive biological environment $[87,88]$. Moreover, its biocompatibility is limited because if the presence of nickel [80], since when corrosion reactions occur, $\mathrm{Ni}$ ions are released and have high potential to cause allergic reaction. $\mathrm{Co}-\mathrm{Cr}-\mathrm{Mo}$ alloys may substitute in certain applications the use of SS316L thanks to their improved mechanical properties and corrosion resistance [80]. Yet, there are some reports that claim $\mathrm{Cr}$ and $\mathrm{Co}$ metal ions are released form such medical devices [89,90], which jeopardizes the long-term safety of Co-Cr-based materials [91]. Several studies have paied attention to nearly equiatomic NiTi alloys because of their unique shape memory and superelasticity properties. However, as mentioned above, Ni-based alloys are biologically active [3], since they possess toxic, allergenic, and carcinogenic properties due to $\mathrm{Ni}$ release $[92,93]$. Ni ions are released spontaneously from the bulk material into surrounding tissues as a result of corrosion processes accelerated, for instance, by fretting wear [94]. CP Ti is used for biological applications and may be produced in dense or porous forms to improve specific bulk properties $[82,83]$. However, Ti6Al4V is the most used Ti alloy because of its higher corrosion resistance [84,95]. Thanks to their high strength-to-weight ratio, improved corrosion resistance, and high biocompatibility, Ti-based materials have been the most widely used biomaterials in both orthopaedic devices and odontological devices [96]. It is well known that a titanium oxide layer is spontaneously formed on the metal surface, improving the biocompatibility of these materials. Still, this layer is often defective $[97,98]$ and, despite the broadly accepted biocompatibility of Ti, the release of Ti microparticles [99] due to corrosion processes, as well as the long-term release of metal ions from metal implants, was reported in in vivo experiments [91]. Hence, it is necessary to change the properties of materials' surfaces, such as chemical stability, to enhance their biological performance [87]. 
The strategy of surface modification with inert $\mathrm{MeN}, \mathrm{MeCN}$, and a-C based coatings has been widely adopted as a solution to improve the corrosion resistance of the different metallic materials mentioned above. In addition, these coatings allow adding other functional properties, such as enhanced osseointegration, which is highly desirable for dental implants, enhanced wear resistance of joint prosthesis, or improved hemocompatibility of cardiovascular devices. Several reports have evaluated the applicability of DLC [94], DLC containing different elements, namely, N [53,57], Pt:Ru [57], Ti [12,52], $\mathrm{Cr}$ [12], compounds such as TiN [71,92,100], AlN [92], TiAlN [92,101], ZrN [19,102], silicon-containing $\mathrm{ZrN}$ [38], CrN [103], ZrCN, and Ag-containing ZrCN [87,104], Hf-containing ZrCN [10] as coatings for different biomedical applications. The main conclusions in relation to each of these coatings are summarized in Table S1 (Suplementary information). In general, these coatings enhance the corrosion resistance of the bare substrates and, thus, they represent a promising solution for medical applications. In fact, these coatings have been proposed and tested for their corrosion resistance in other applications, and the results suggest a favourable effect in delaying the corrosive degradation of metallic substrates, as previously reviewed.

In addition to the influence of the materials' properties on the corrosion behaviour, the body fluids are very complex and, thus, simulated body fluids represent a more complex corrosive environment, which can deteriorate the corrosion performance offered by coatings in neutral electrolytes. The next section will be focused on the influence of simulated body fluids and their complex compounds on the corrosion behaviour of $\mathrm{MeN}, \mathrm{MeCN}$, and a-C based coatings.

\subsection{Corrosion Behaviour of Coatings in Simulated Body Fluids and the Influence of Bio-Components on the Electrochemical Properties}

In the electrochemical processes related to metal-coated systems for biomedical applications, besides the interaction between different parameters already discussed in the previous sections, such as substrate-coating assembly, substrate and coating chemistry, and film morphology, other factors, such as electrolyte chemical composition and electrolyte temperature and $\mathrm{pH}$, should be considered. In the particular case of biomedical implants testing, the selection of the electrolyte represents a fundamental issue, since the body fluids are not simple saline solutions but instead complex environments containing a variety of anions and cations, large molecules, and cells, and each of them plays an important role in the corrosion processes. In this sense, the chemical composition of the body fluid in contact with the material to be used in each application, e.g., blood in the case of cardiovascular devices, urine in the case of devices for the urinary system, saliva in the case of dental implants, and synovial fluid in the case of synovial joints, like hip or knee implants, must be considered in the corrosion tests. The main applications of metal-coated $M e N, M e C N$, and a-C coatings are related to knee and hip prosthesis and dental implants; thus, in order to achieve a realistic understanding of the materials to be applied in these applications, the chemical composition of synovial fluid and saliva must be considered. Synovial fluid is composed of filtrate plasma, glycoproteins, and hyaluronans. Saliva is mainly composed of water $(99 \%)$ and solids $(1 \%)$, which can be inorganic $\left(\mathrm{Na}^{+}, \mathrm{Cl}^{-}, \mathrm{K}^{+}, \mathrm{HCO}_{3}^{-}\right)$ and organic (ptyalin, lingual lipase, kallikrein, lysozyme, urea, uric acid, cholesterol, and mucin). Figure 7 shows a statistical analysis of the electrolytes used in the reports related to $M e N-, M e C N-$, and a-C-based coatings proposed for different biomedical applications. 


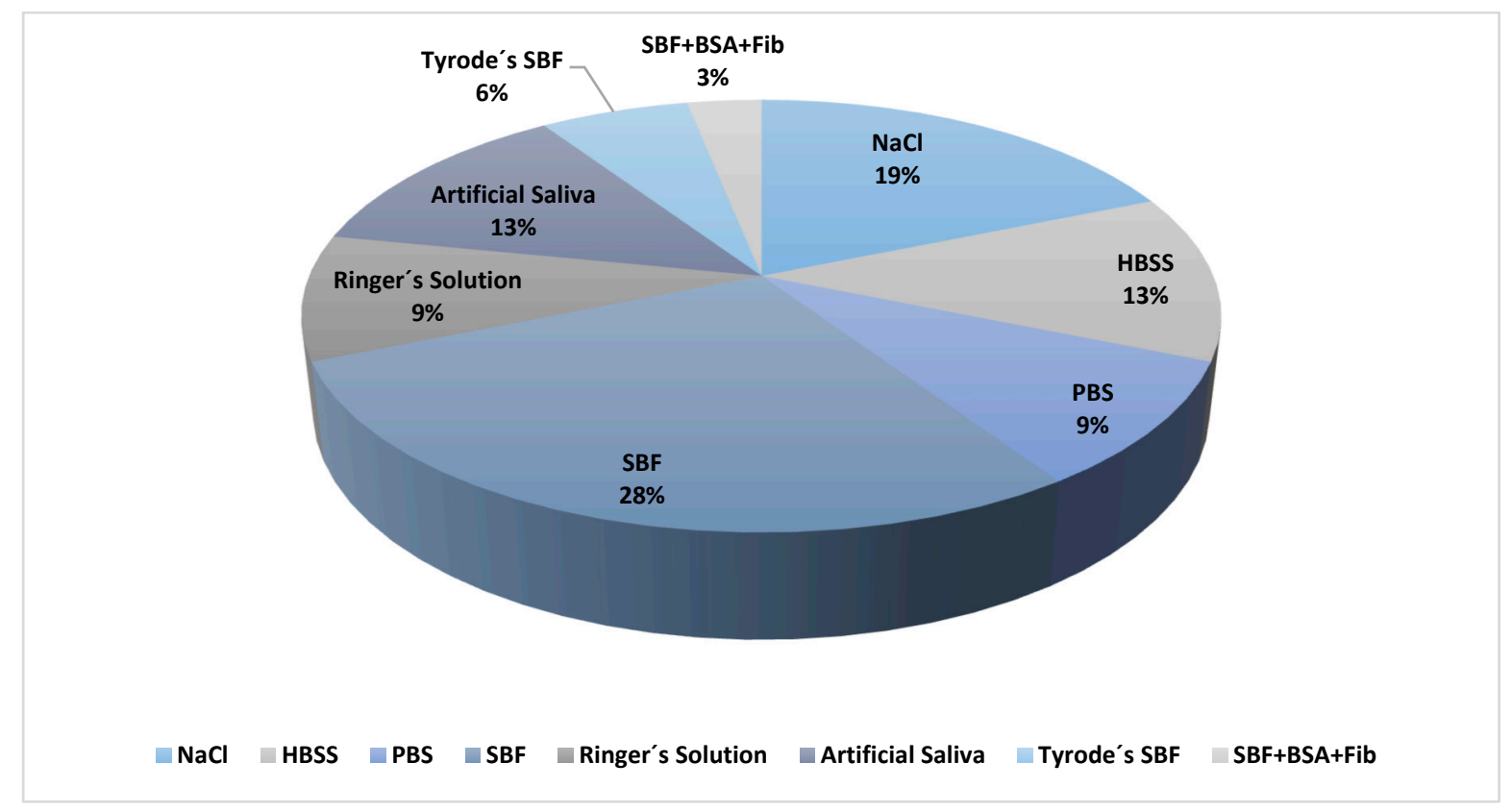

Figure 7. Main electrolytes used in corrosion testing of $\mathrm{MeN}-, \mathrm{MeCN}-$ and a-C-based coatings for biomedical applications.

As depicted in Figure 7 some of the papers used simple saline solutions containing $\mathrm{NaCl}$, with varying concentrations of the salt (from $0.9 \%[11,87,100,104]$, which resembles the physiological concentration, up to $3 \%$ of $\mathrm{NaCl}$ [103]), while the other electrolytes were represented by more complex saline solutions (phosphate buffer solution (PBS) [81,105], Hank's balanced saline solution (HBSS) [52,57], or simulated body fluid (SBF) $[12,92,106,107])$, which can contain some organic molecules such as in Tyrode"s simulated body fluid and AFNOR S90-701 artificial saliva $[19,102]$ and Fusayama Mayer artificial saliva [101]. The addition of proteins to SBF was also performed. The influence of proteins on the corrosion behaviour of metallic implants has been widely studied by several authors, and it is claimed that the presence of proteins and other organic compounds influences the corrosion rate of metallic implants. Several phenomena due to the presence of the organic surface layer can occur, which influence the corrosion rate [108], namely:

(i) Biological molecules can consume the products of the anodic and cathodic reactions, e.g., through the formation of metal-proteins following the binding with $\mathrm{Me}^{+}$ions which are transported away from the implant surface. This will change the equilibrium across the double layer and favour the metal dissolution.

(ii) Biological molecules can interact with the charges formed at the interface and affect the electrode potential, which will influence the stability of the passive oxide layer;

(iii) The presence of a surface layer will influence the availability of oxygen and hydrogen, thus influencing the rate of the cathodic reaction, which can increase or decrease the rate of the anodic reactions.

In addition to the presence of the common elements found in synovial fluid, bacteria can also be present as well as phagocytic cells, which also play a specific role in the corrosion process.

The choice of more complex electrolytes, resembling the body fluids, allows obtaining a more realistic understanding of the behaviour of materials in the final applications; nevertheless, it limits the interpretation of the components' influence on the corrosion behaviour of the materials. Thus, the choice of adequate electrolytes is a complex issue. 
All these features can determine the electrochemical performance of a biomaterial. In the following sections, the effect of complex saline solutions with/without proteins and/or organic compounds on the electrochemical characteristics of different biomedical devices is summarized.

\subsubsection{Dental Implants}

The number of reports that propose the use of $\mathrm{MeN}-, \mathrm{MeCN}-$, or a-C-based coatings for dental implant applications is scarce. In fact, the application of sputtered coatings focuses mainly on the use of $\mathrm{MeO}$ - and $\mathrm{MeON}$-based coatings, since, despite the corrosion protection provided by these coatings, they are found to be bioactive, thus enhancing the osseointegration process. Yet, Krishnan and co-workers [101] investigated the corrosion properties of a $\beta$-Ti alloy coated with TiAlN and WC:C in artificial saliva, without and with a fluoride immersion cycle before the corrosion studies. It was noticed that, even though both coatings improved the corrosion performance of the $\beta$-Ti alloy, all materials had reduced ability to resist corrosion when subjected to fluoride exposure. The exposure to fluorides dissolved the passive layer as a consequence of the high number of defects/imperfections, as well as of their high grain boundary defects, exposing the substrate to corrosion. Still, the reduction of corrosion protection was lower for both tested coatings (TiAlN and WC:C) when compared with uncoated $\beta$-Ti substrate, showing the best behaviour for TiAlN and revealing its nobler character. As it can be seen in Figure 8, after fluoride immersion, both uncoated $\beta$-Ti and WC:C surfaces were exposed and deteriorated by fluoride-induced corrosion, while TiAlN continued to exhibit a corrosion-free surface.

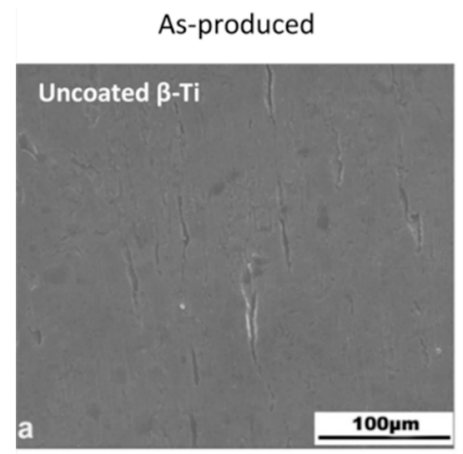

After fluoride immersion cycle
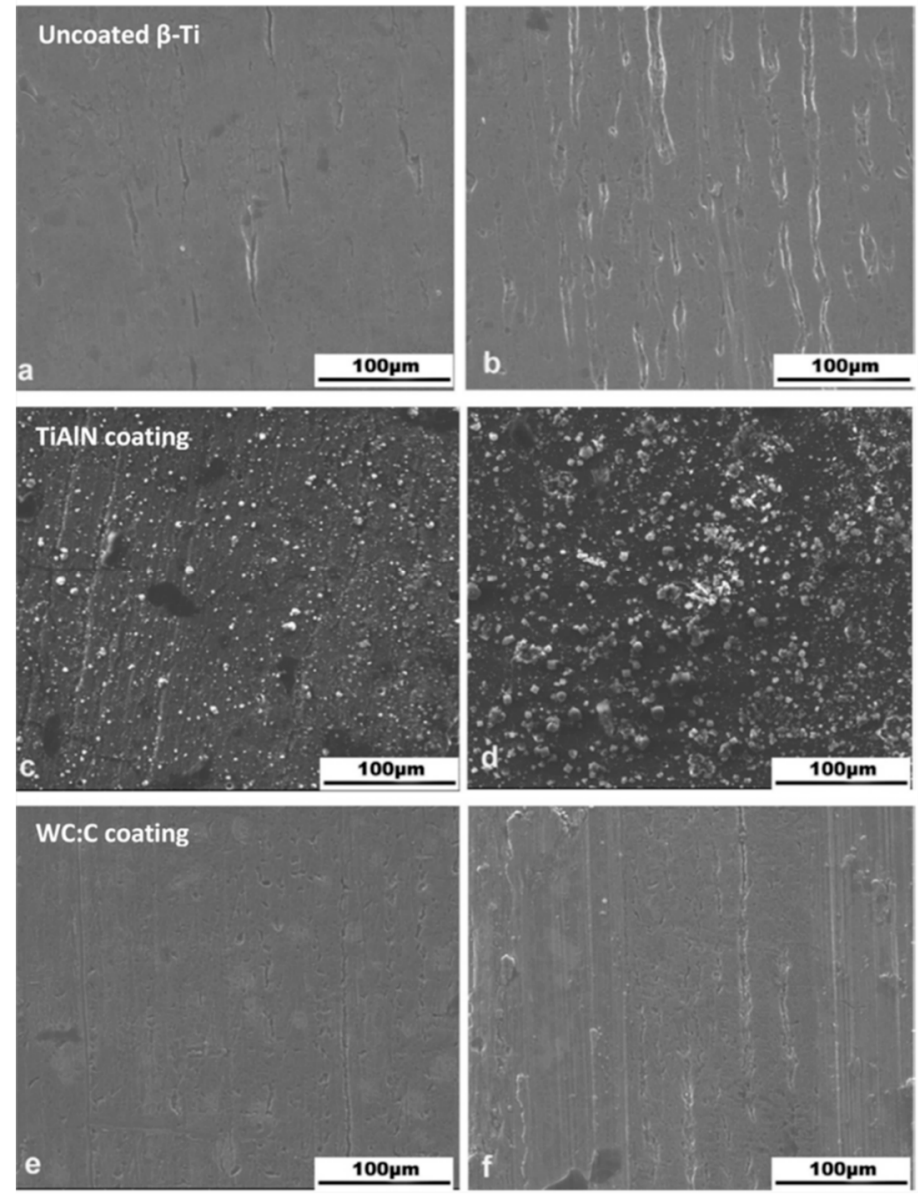

Figure 8. Surface analysis of $(\mathbf{a}, \mathbf{b})$ uncoated $\beta$-Ti alloy, $(\mathbf{c}, \mathbf{d})$ TiAlN, and $(\mathbf{e}, \mathbf{f})$ WC:C coatings $(\mathbf{a}, \mathbf{c}, \mathbf{e})$ before and $(\mathbf{b}, \mathbf{d}, \mathbf{f})$ after a fluoride immersion cycle. Adapted from [101]. 


\subsubsection{Orthopaedic Implants}

As depicted in the graph of Figure 7, most of the studies related to the evaluation of the electrochemical properties of $\mathrm{MeN}-, \mathrm{MeCN}-$, and a-C-based coatings for orthopaedic implant applications used different saline solutions. Hang et al. [109] evaluated the electrochemical behaviour of DLC-coated NiTi in PBS solutions containing bovine serum albumin (BSA) and fibrous proteins (Fib). The authors found that the proteins enhanced the corrosion resistance of DLC coatings, being this effect more pronounced in the case of BSA. The adsorption and formation of a protein layer at the substrate/electrolyte interface, in the micro-pores, and on micro-pore walls can cover the DLC surface and inhibit the mass transportation of the corrosion products. The better improvements obtained with BSA were attributed to the higher coverage of micro-pores, which was reported to be about $48 \%$ for BSA and 43\% for Fib. Hauert et al. [110] evaluated the adhesive failure of DLC-coated Ti6Al4V by performing Rockwell C indentations followed by immersion in PBS and Hyclone wear test fluid, which contains salts and proteins. The effect of both electrolytes on the coatings delamination rate, promoted by the corrosive environment, was evaluated. Coating delamination promoted by the dissolution of the silicon interlayer occurred in Hyclone test fluid at a rate of $145 \mu \mathrm{m}$ per year, while no or only little delamination was observed in PBS. The authors postulated that the presence of proteins in Hyclone may be responsible for the buildup of crevices. The proteins hinder liquid exchange and thus support the buildup of crevice corrosion conditions, which leads to coatings delamination, promoted by corrosion mechanisms. The final conclusions were contradictory; nevertheless, it should be pointed out that the test methodologies in both studies were completely different.

\subsection{Commercial Applications of MeN- and a-C-Based Coatings and Major Limitations Caused by Corrosion-Induced Failure}

Surface modification of different biomaterials has been adopted as a strategy for the improvement of different indwelling devices, allowing the enhancement of their lifetime. Table 1 summarizes the main commercial coatings found in the market, as well as the advantages provided by these coatings in each application.

Table 1. Commercial coatings already in the market.

\begin{tabular}{|c|c|c|c|}
\hline Application & Coating & Properties & Producer Companies \\
\hline Orthopedic Implants & $\mathrm{TiN}, \mathrm{CrN}, \mathrm{ZrN}, \mathrm{TiNbN}$ & $\begin{array}{c}\text { Reduction in the release of ions } \\
\text { Wear Reduction } \\
\text { Low Friction }\end{array}$ & $\begin{array}{l}\text { Ionbond, Balzers } \\
\text { Oerlikon, Ceramed, } \\
\text { Endotek }\end{array}$ \\
\hline Dental Implants & $\begin{array}{c}\text { TiN, AlTiN, } \\
\text { TiAlN, } \\
\text { a-C:H, } \\
\text { a-C:H:W, CrN }\end{array}$ & $\begin{array}{l}\text { Improved screw adjustability } \\
\text { Reduction of torque at the } \\
\text { application of the screws } \\
\text { Cost savings due to easier and } \\
\text { faster exchange of the abutment } \\
\text { screws and implants }\end{array}$ & Balzers Oerlikon \\
\hline Cardiovascular Implants & DLC & $\begin{array}{c}\text { Ion release reduction, } \\
\text { Low friction, Hemocompatibility }\end{array}$ & Balzers Oerlikon \\
\hline $\begin{array}{l}\text { Ureteral } \\
\text { Stents }\end{array}$ & DLC & $\begin{array}{c}\text { Reduced friction } \\
\text { Enables smooth introduction } \\
\text { Reduced risk of infection } \\
\text { and encrustations }\end{array}$ & Optimed \\
\hline
\end{tabular}

A large number of pre-clinical reports can be found in the literature, which points out the excellent results achieved with the above-mentioned coatings for the different applications indicated in Table 1. These results are nicely reviewed in references [111,112]. Among the different applications, the use of these coatings in joint prosthesis has attracted a lot of efforts. In fact, this is one of the most common applications of $\mathrm{MeN}$-based coatings in the biomedical industry. Despite a large number of laboratory and preclinical studies on these coatings and their long-date use, the number of clinical case studies is still scarce, and controversial findings are reported in the existing ones. According to the reported clinical 
studies, the main cause of failure of these coatings is related to adhesive failure, which is promoted by the occurrence of electrochemical corrosion processes. These reports are summarized in this section, which focuses on the analysis of TiN- and DLC-coated retrieved orthopaedic joint prostheses.

Regarding TiN coatings, several reports indicate a survival rate above 90\% [113-117], nevertheless other reports indicate lower survival rates and worse performance in relation to uncoated materials [114,118]. A more detailed analysis of retrieved TiN coatings is given in [118-120]. In all these reports, the failure of the coating is attributed to delamination promoted by a combination of corrosion and mechanical damage. Harman et al. [119] reported a case study regarding the wear performance of TiN coating on a retrieved hip implant obtained postmortem from a low-demand patient one year after total hip arthroplasty. The hip implant components consisted of a polyethylene liner in the Ti6A14V acetabular cup with TiN coating, a TiN-coated Ti6AI4V femoral stem, and a modular TiN-coated Ti6Al4V head (Buechel-Pappas System, Endotec). Gross examination showed a dull grey discolouration of the gold-coloured TiN coating localized to the post superior region of the femoral head. A more detailed analysis revealed the presence of smooth coating with 1-2 $\mu \mathrm{m}$ voids uniformly dispersed on the surface of the coating. In the discoloured areas, larger voids with sizes up to $10 \mu \mathrm{m}$ were observed, and the presence of pure Ti droplets was detected in some voids. Evidence of pure Ti and Ti6Al4V debris adherent to the TiN coating was found. The retrieval analysis showed that wear debris originated from a TiN -oated femoral head as delaminated surface asperities and manifested as adhesive wear on the articular surface. Moreover, Raimondi et al [61] evaluated the in-vivo wear performance of prosthetic femoral heads with TiN coating in a study focused on the analysis of four TiN-coated prosthetic femoral heads collected at revision surgery together with patient data. The analyses were performed 18 to 96 months after hip arthroplasty in femoral stems built with a Ti6Al4V alloy and implanted with modular TiN-coated femoral heads articulating on ultra-high molecular weight polyethylene (UHMWPE) counterfaces. Two of the four examined components showed a macroscopically intact TiN coating 6 to 8 years after implant, while TiN fretting and coating breakthrough occurred in two of the four examined components. The main cause of this coatings failure was related to coatings delamination, which resulted in the following events, all proved to adversely affect the implant clinical outcome: (i) release of TiN fragments in the periprosthetic tissues; (ii) release of metallic particulate from the titanium substrate; (iii) increase of the head surface roughness affecting the counterface debris production rate. Further, Lapaj et al. [120] performed a retrieval analysis of 11 femoral heads made of a TiN-coated TiAl6V4 alloy (articulating in vivo for 1-56 months) against the UHMWPE counterparts. No gross failure of the TiN coating was observed; nevertheless, all implants had defects typical of physical vapor deposition (PVD) coatings, such as pinholes, small titanium droplets, and blisters with delaminated coating. The authors found that the most common defects were small pinholes (diameter of 1-2 $\mu \mathrm{m}$ ) which were scattered over the entire surface of all samples. A smaller number of uniformly distributed, round (diameter 5-10 $\mu \mathrm{m}$ ) defects containing droplets of titanium were also present in all implants. On both weight-bearing and non-weight-bearing parts of the heads, film cracking adjacent to pinholes and titanium droplets was observed, as well as the presence of larger (diameter 15-40 $\mu \mathrm{m}$ ) irregular defects, with coating delaminated from the substrate material. The SEM and energy dispersive spectroscopy (EDS) analyses reported by the author are depicted in Figure 9. 


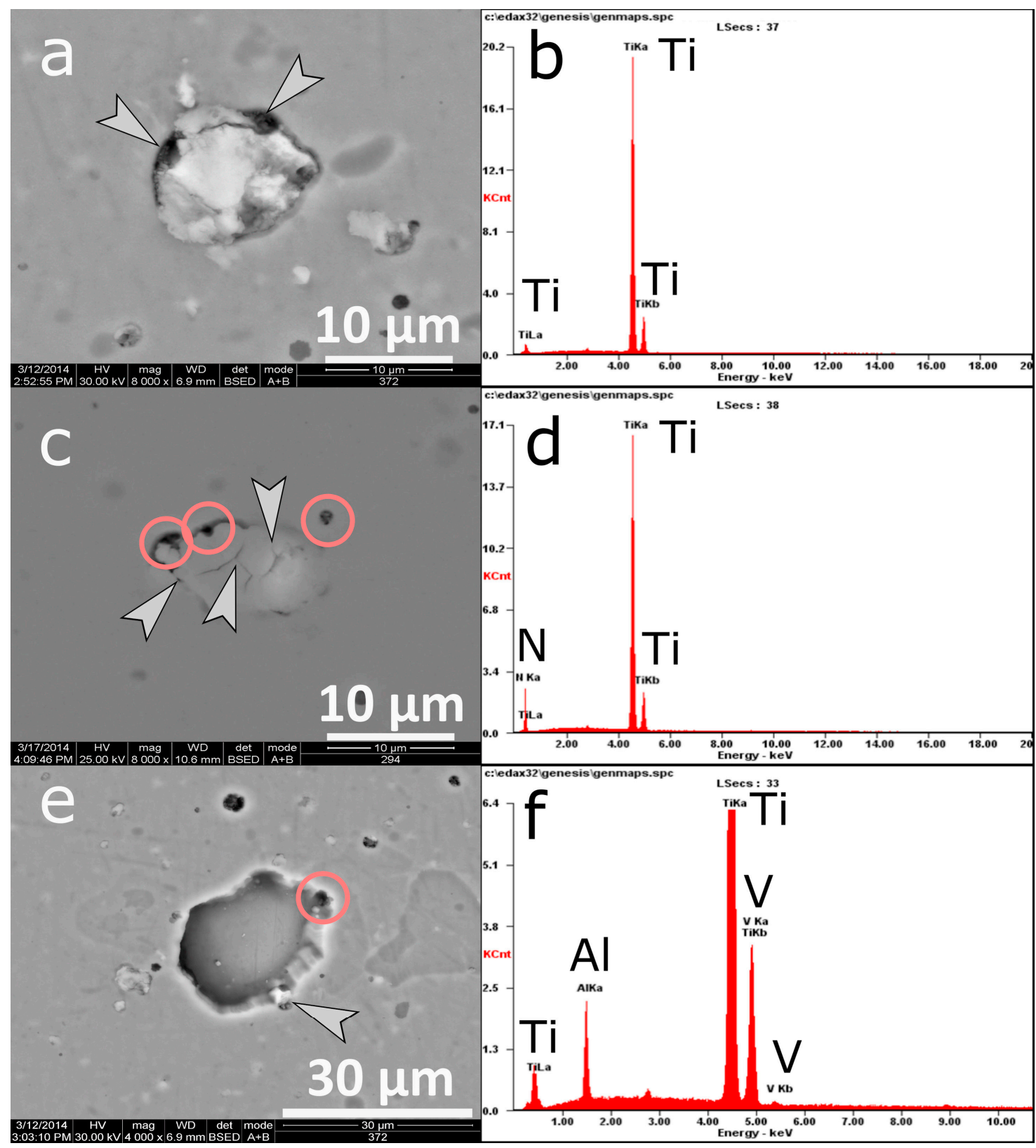

Figure 9. SEM micrographs of defects observed in TiN-coated Ti6Al4V. (a) Titanium droplet embedded into the coating; the arrows indicate missing coating adjacent to the droplet; (b) EDX analysis of the droplet; (c) cracking of coating adjacent to pinholes (in circles); (d) EDX analysis of cracked coating; (e) blister with debonded coating, formed adjacent to a pinhole (in the circle) and a titanium droplet (arrow); (f) EDX analysis of the bottom of a blister demonstrating the composition of the TiAl6V4 substrate alloy. Reproduced from [120].

Taeger et al. [121] reported a comparative study of DLC and $\mathrm{Al}_{2} \mathrm{O}_{3}$ femoral heads articulating against polyethylene in total hip-joint arthroplasties (THA). In this study, 101 THA with DLC-coated Ti6Al4V femoral heads and $101 \mathrm{Al}_{2} \mathrm{O}_{3}$ heads were compared. Survivorship analysis for aseptic loosening 8.5 years following implantation resulted in a significant difference between the groups, with a $54 \%$ survival for DLC/PE compared to $88 \%$ for $\mathrm{Al}_{2} \mathrm{O}_{3} / \mathrm{PE}$ bearings. The main cause of failure of the DLC coatings was attributed to the delamination of the carbon layer, which led to excessive debris of polyethylene and, in some cases, of the metallic substrate of the heads. The retrieval analysis of the implants revealed the presence of small pits (see Figure 10a), visible with the naked eye. In few cases 
(6/19), disastrous abrasion of polyethylene caused by delaminated DLC coating particles, which also caused excessive wear of the metallic substrate of the head, was visible (see Figure 10b).
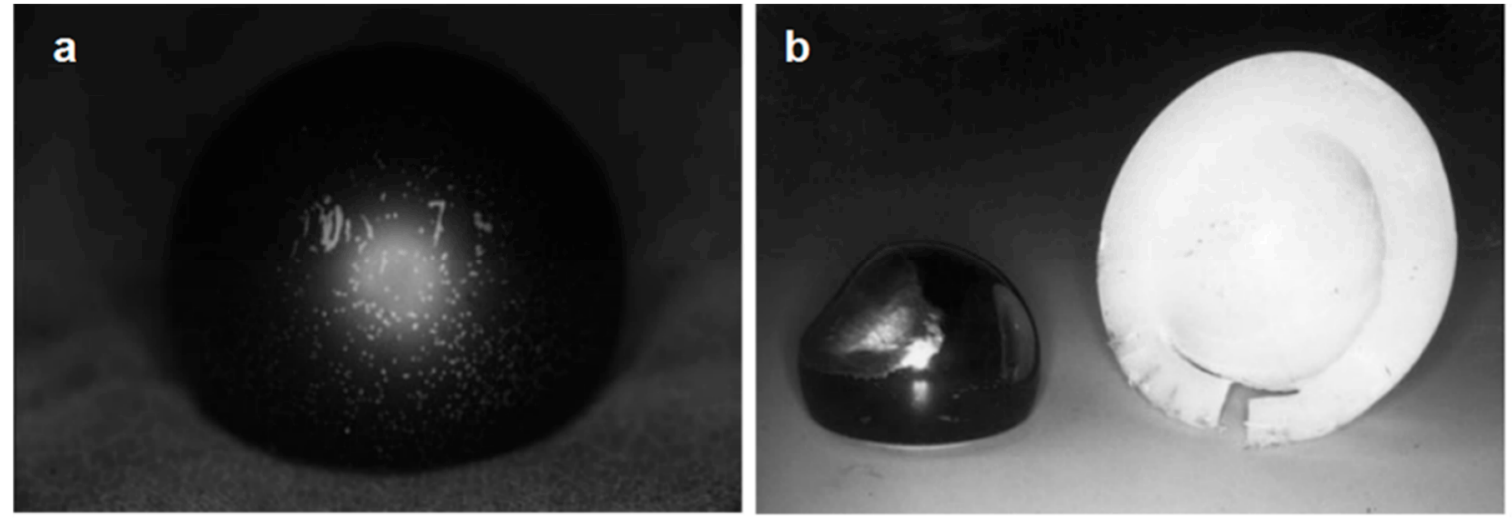

Figure 10. (a) Retrieved DLC-coated head: Lateral and cranial aspect articulated with the acetabular component (polyethylene). Numerous pits in the formerly articulating surfaces, revealing metallic substrate underneath. (b) DLC-coated head and corresponding acetabular surface. Substantial defects in the spherical deformed polyethylene caused by DLC particles. Consecutive abrasion of the metallic substrate (head) and metal backing of the socket. Adapted from [121].

Several of these Ti6Al4V-coated femoral heads were studied by Hauert et al. [110,122] in order to investigate the reasons of the failure. The authors evaluated the coatings chemical composition by XPS analysis and found a multilayer structure, being the coating composed of a DLC amorphous carbon layer, several Si-doped layers, and an adhesion-promoting Si interlayer. The focused ion beam transverse cross sections revealed that the delamination of the coatings was caused by the dissolution of the silicon adhesion interlayer. Such common coatings defects, such as pinholes, droplets, or blisters, as discussed before, act as diffusion paths for the penetration of body fluids, exposing the lower nobler adhesion interlayer and, thus, allowing its corrosion dissolution and compromising the long-term viability of the devices.

Joyce et al. [123] also evaluated a failed ex vivo metal-on-metal metatarsophalangeal joint which was composed of $\mathrm{CoCr}$ for both the metatarsal and the phalangeal components, coated with DLC coatings; the stems were covered with hydroxyapatite to encourage bone ingrowth. The joint prosthesis was removed 4 years after implantation, and at this time, there was a black staining of the surrounding joint synovium and osteolysis of the bone ends. These implants were also studied by Hauert et al. [124] who evaluated the coatings in-depth chemical composition, reporting that the coating was composed of a $180 \mathrm{~nm}$-thick DLC film and a circa $120 \mathrm{~nm}$-thick silicon-based adhesion-promoting interlayer on a CoCrMo base material. SEM analysis revealed, again, the corrosion dissolution of the Si adhesion interlayer through the coatings defects, as the main mechanism of the coating's adhesive failure.

Despite the scarce number of clinical studies on ceramic coatings' performance, several conclusions can be withdrawn: (i) The main cause of failure of TiN and DLC coatings is related to coatings delamination, which results in an increased wear of polymeric counterparts and (ii) The delamination of the coating occurs mainly in regions were defects are present, namely, pinholes and droplets, which allows fluids penetration favouring the corrosion of the interlayers. In the retrieval analysis performed by Lapaj et al. [120], the adhesion of the coating was previously tested by the manufacturer following the VDI 3824 guidelines, being the adhesive strength classified as HF1 and HF2, which indicates a good adhesive strength. Nevertheless, the main issues in the retrieved implants were related to coatings delamination, which suggests that other mechanisms were involved in coatings' adhesive failure, which were not predicted either in the above-mentioned adhesion tests nor in the evaluation of coatings' reliability in hip simulators. 
The clinical studies previously reviewed point at the occurrence of coatings' adhesive failure, with a consequent loss of the promising functionality of the coatings. The above-mentioned results indicate that the delamination of the coating is promoted by corrosion mechanisms which occur at sites where defects are present. Most of the reports dealing with ceramic coatings corrosion behaviour evaluate the coatings corrosion behaviour, and some of them provide an analysis of coatings' defects after electrochemical tests, in order to determine the main corrosion mechanisms. Nevertheless, this analysis is only provided in few papers, and the delamination of coatings after corrosion tests has not received much attention. In fact, in the starting point, this adhesive failure is only local and occurs mainly in points where defects are present, being the size of these defects and delamination zones in the micrometric range. However, these small defetcs assume great importance in biomedical applications, namely, in joint prosthesis, since the evolution of these microscopic defects leads to visible delamination of large areas on the implant surface. Coatings' delamination originated from corrosion processes has been reported in few papers, and different mechanisms have been reported. Komotori et al. [125] evaluated the corrosion response of SP700 (Ti-4.5Al-3V-2Fe-2Mo) and Ti6Al4V alloys with and without surface treatments by thermal oxidation and deposition of TiN coatings. In this work, the effect of prior mechanical surface damage on the corrosion behaviour (in $0.89 \mathrm{wt} . \%$ of $\mathrm{NaCl}$ ) was simulated by scratching the samples with a diamond Rockwell $\mathrm{C}$ indenter. The TiN coatings surface after the corrosion tests were analyzed by SEM, and three types of corrosion were detected: (i) adhesive coatings failure at sites of prior abrasion damage, (ii) pitting originating from droplets produced during coating deposition, and (iii) pin-hole defects which led to blistering and localized loss of TiN, being the last one the most frequent type of observed failure. Coatings' adhesive failure was explained through a model where pitting and galvanic corrosion took place. A schematic representation of the model is depicted in Figure 11.

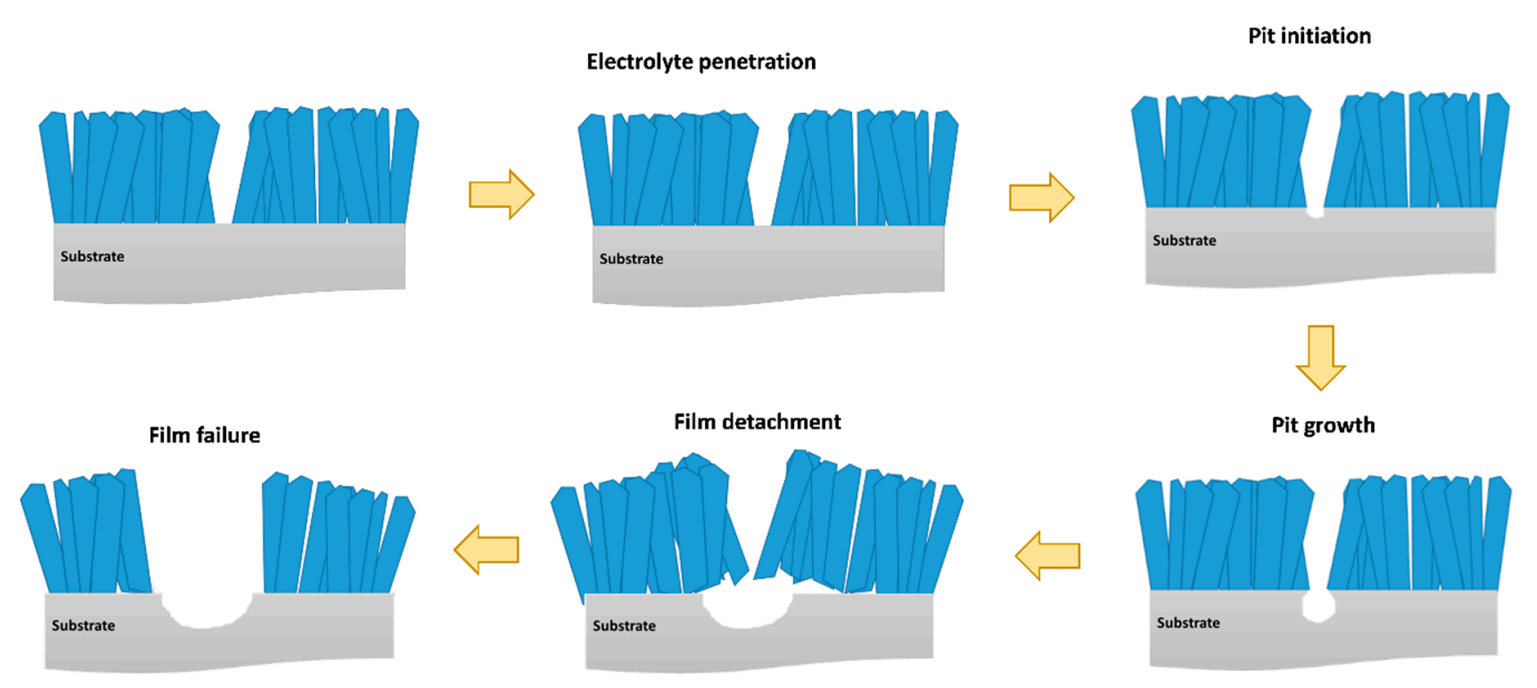

Figure 11. Coatings' delamination promoted by corrosion processes.

The evaluation of coatings' delamination in DLC coatings has been an extensive research focus of Hauert and co-workers $[110,122,124]$. The group started the research on DLC coatings failure by analyzing the joint implants reported by Taeger et al. [121] and Joyce et al. [123], previously reviewed. Besides the analysis of these retrieved implants, the authors researched DLC coatings failure mechanisms promoted by interface dissolution, which was found as the main mechanism of coatings in vivo failure in the retrieved implants. Falub et al. [126] reported a quantitative in vitro method to predict the lifetime of DLC coatings adhesion to CoCrMo substrate, which is typically used in biomedical implants immersed in PBS solution at $37^{\circ} \mathrm{C}$. These tests are used to evaluate the coatings after deposition in order to determine the interface fracture toughness and the effects of environmental conditions, such as exposure to varying humidity and ion concentrations or human 
body natural potential changes are not considered. Yet, Falub et al. [126] showed that the even static environmental conditions play an important role in the evolution of coatings adhesion around the Rockwell indentation. The time evolution of the $2 \mu \mathrm{m}$ DLC coating on a CoCrMo alloy immersed in PBS solution is shown in Figure 12.
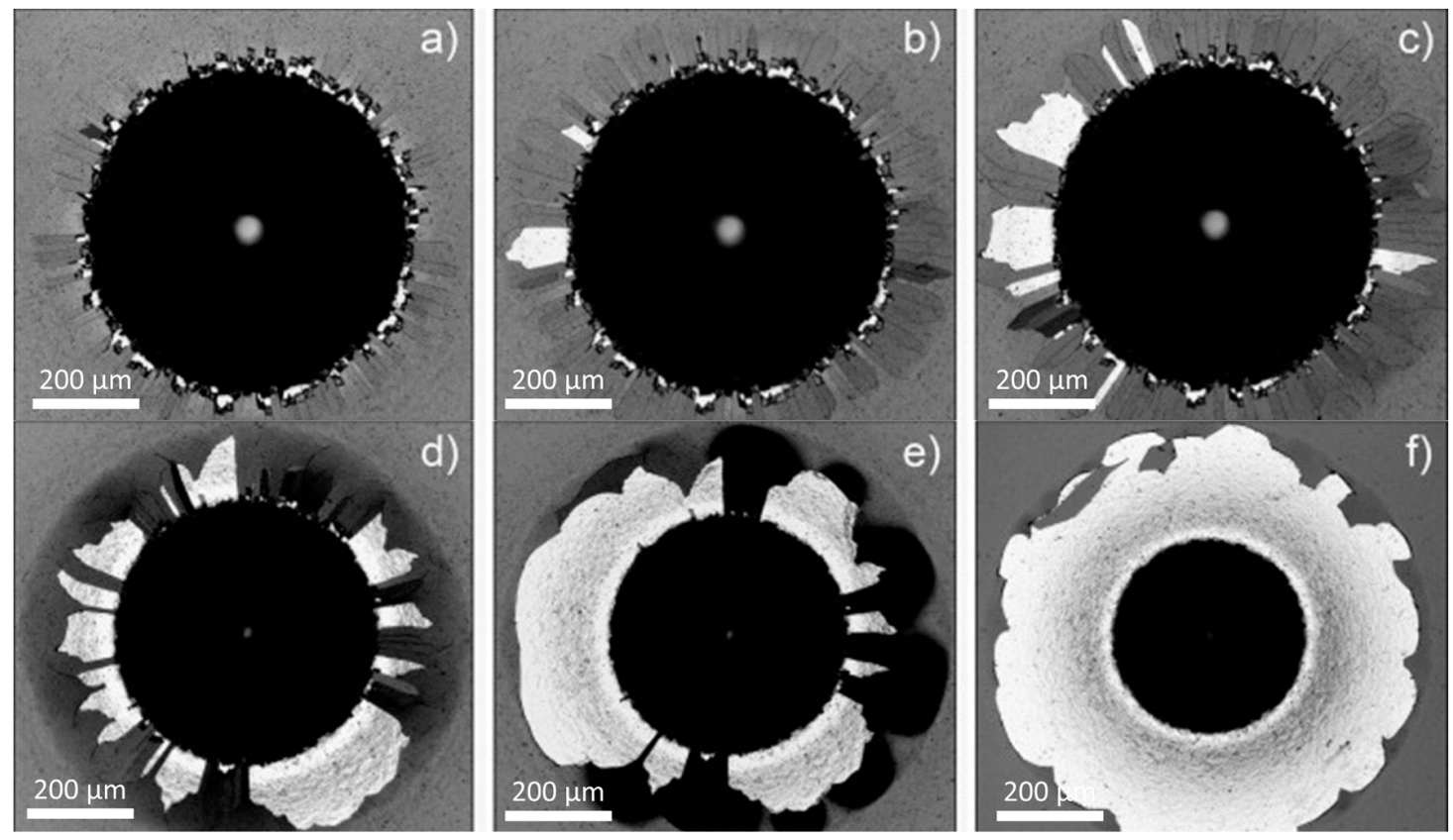

Figure 12. Delamination area evolution of $2 \mu \mathrm{m}$-thick DLC coating on CoCrMo around Rockwell indentation using a load of $1500 \mathrm{~N}$ : (a) $t=0$, (b) $t=15 \mathrm{~min}$, (c) $t=65 \mathrm{~min}$, (d) $t=4 \mathrm{~h} 25 \mathrm{~min}$, (e) $t=16 \mathrm{~h}$ $50 \mathrm{~min},(\mathbf{f}) t=160 \mathrm{~h} 40 \mathrm{~min}$. Between immersions, the coating was immersed in PBS at $37^{\circ} \mathrm{C}$. Reproduced from [126].

The optical micrographs shown in Figure 12 clearly show that the delamination area around the indentation increased with time, thus suggesting that the delamination of the coating is a result of combined applied load and corrosion process induced by the PBS electrolyte. The corrosion mechanism was attributed to stress-corrosion cracking. Cracks resulting from residual or applied stress cause corrosion reactions at the interface, which leads to coating adhesion decrease and subsequently delamination.

\subsection{Conclusion}

In summary, the electrochemical corrosion behaviour of films deposited by magnetron sputtering is mainly affected by three characteristics: (i) composition, (ii) morphology, and (iii) architecture. These characteristics are, in turn, affected by intrinsic and extrinsic features of the system substrate-film-electrolyte, such as the type of film growth, defects, density, phases, resistivity, film-substrate adhesion, among others, as summarized in Figure 13. As a result, the great difficulty of controlling the electrochemical corrosion of magnetron-sputtered films lays on the fact that some of these features are interconnected, and thus, by changing one, the others will be modified. For example, the composition of the films (together with the deposition conditions) can largely alter their columnar or granular growth, as well as the porosity and boundaries density in the materials. Changing the architecture of the coatings by creating bi-layers or multilayers may alter the porosity and defects of the system, also affecting the electrochemical corrosion. Moreover, the type of substrate not only modifies the growth of the films, but also activates galvanic processes within the films and/or alters their adhesion strength. These relations make crucial the study of the effects of small changes in the production process of MS coatings on their electrochemical corrosion behaviour. 


\section{ELECTROCHEMICAL CORROSION IN MAGNETRON SPUTTERED FILMS}
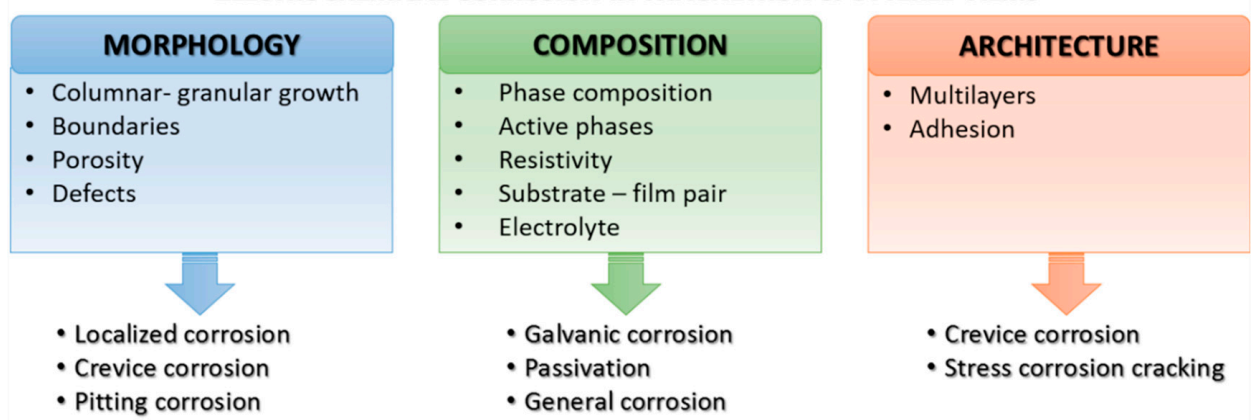

Figure 13. Characteristics of magnetron.sputtered films affecting the electrochemical corrosion.

When considering biomedical applications, since the human body represents a very complex and demanding system, the materials must be carefully selected, and the protection of metallic implants from corrosion is a demanding requirement. In spite of the dependence of the corrosion behavior on intrinsic and extrinsic features of the biomaterial, the body fluids are very complex and, thus, simulated body fluids, comprising organic compounds, proteins and/or cells, represent a very complex corrosive environment, which can deteriorate the corrosion performance offered by coatings in neutral electrolytes. Despite a large number of laboratory and preclinical studies on these coatings and their long-date use, the number of clinical case studies is still scarce, and controversial findings are reported in the existing ones. Still, some conclusions can be withdrawn: (i) The main cause of failure in coatings is related to coating delamination; (ii) The delamination of the coatings occurs mainly as a result of adhesive failure due to the occurrence of electrochemical corrosion processes, where permeation of the coating is promoted either by the coating's properties (morphology, architecture, and defects) or by wear.

Supplementary Materials: The following are available online at http://www.mdpi.com/2079-6412/9/10/682/s1, Table S1: Electrochemical corrosion studies of magnetron sputtered films. References [127-130] are cited in supplementary materials.

Author Contributions: All authors have contributed for the conpectualization, methodology, formal analysis and funding acquisition of the present review paper. S.C. (Sebastian Calderon), C.F.A.A. and N.K.M. wrote the original document that was reviewed by A.C., S.C. (Sandra Carvalho), S.C. (Sebastian Calderon) and C.F.A.A. performed the review visualization. A.C. and S.C. (Sandra Carvalho) supervised the research.

Funding: This research is sponsored by FEDER funds through the program COMPETE-Programa Operacional Factores de Competitividade and by the Portuguese Foundation for Science and Technology (FCT) in the framework of the Strategic Funding UID/FIS/04650/2019, andUID/EMS/00285/2013 and in the framework of PTDC/CTM-NAN/4242/2014 and PTDC/NAN-MAT/30789/2017. The authors also thank the financial support by the Portuguese Foundation for Science and Technology (FCT) in the framework of the HEALTHYDENT (co-financed via FEDER (PT2020) POCI-01-0145-FEDER-030708 and FCT (PIDDAC) and the NANOXYPACK POCI-01-0145-FEDER-030789 projects. This research was supported by Norte Regional Operational Program 2014-2020 (Norte2020) through the European Regional Development Fund (ERDF) Nanotechnology-based functional solutions (NORTE-01-0145-FEDER-000019) and through European Social Fund (FSE), under the National Doctoral Program in "Surfaces Engineering and Protection", NORTE-08-5369-FSE-000047. The authors would like to acknowledge the EU Framework Programme for Research and Innovation H2020, scheme COFUND - Co-funding of Regional, National and International Programmes, under Grant Agreement 713640. The CENTRO Program is also acknowledged through the projects MATIS - CENTRO-01-0145-FEDER-000014 and On-Surf - POCI-01-0247-FEDER-024521.

Acknowledgments: In this section you can acknowledge any support given which is not covered by the author contribution or funding sections. This may include administrative and technical support, or donations in kind (e.g., materials used for experiments).

Conflicts of Interest: The authors declare no conflict of interest. 


\section{List of Abbreviations}

\begin{tabular}{ll} 
a-C & Amorphous carbon \\
BSA & Bovine serum albumin \\
CP & Commercially pure \\
CPE & Constant phase element \\
DLC & Diamond-like carbon \\
EIS & Electrochemical impedance spectroscopy \\
EDX & Energy dispersive x-ray spectroscopy \\
$R_{c}$ & Film resistance \\
FIB & Focus ion beam \\
HBSS & Hank's balanced salt solution \\
Z & Impedance \\
MS & Magnetron sputtering \\
OCP & Open circuit potential \\
PBS & Phosphate buffer solution \\
$R_{p}$ & Polarization resistance \\
PT & Potentiodynamic test \\
SCE & Saturated calomel electrode \\
SEM & Scanning electron microscopy \\
SBF & Simulated body fluid \\
SS316L & Stainless steel 316 L \\
SHE & Standard hydrogen electrode \\
THA & Total hip-joint arthroplasty \\
Rct & Transfer resistance \\
$M e C N$ & Transition metal carbonitride \\
$M e N$ & Transition metal nitride \\
$M e C$ & Transition metal carbide \\
& \\
\hline SE &
\end{tabular}

\section{References}

1. Čekada, M.; Panjan, P.; Kek-Merl, D.; Panjan, M.; Kapun, G. SEM study of defects in PVD hard coatings. Vacuum 2007, 82, 252-256. [CrossRef]

2. Zykova, A.; Safonov, V.; Walkowich, J.; Rogowska, R.; Yakovin, S. Corrosion properties of nitride, oxide and multilayer coatings on stainless steel and titanium-based substrates. J. Phys. Conf. Ser. 2010, 223, 012024. [CrossRef]

3. Batory, D.; Blaszczyk, T.; Clapa, M.; Mitura, S. Investigation of anti-corrosion properties of Ti: C gradient layers manufactured in hybrid deposition system. J. Mater. Sci. 2008, 43, 3385-3391. [CrossRef]

4. Franco, C.V.; Fontana, L.C.; Bechi, D.; Martinelli, A.E.; Muzart, J.L.R. An electrochemical study of magnetron-sputtered Ti- and TiN-coated steel. Corros. Sci. 1998, 40, 103-112. [CrossRef]

5. Wu, G.; Wang, X.; Ding, K.; Zhou, Y.; Zeng, X. Corrosion behavior of Ti-Al-N/Ti-Al duplex coating on AZ31 magnesium alloy in $\mathrm{NaCl}$ aqueous solution. Mater. Charact. 2009, 60, 803-807. [CrossRef]

6. Altun, H.; Sen, S. The effect of DC magnetron sputtering AlN coatings on the corrosion behaviour of magnesium alloys. Surf. Coat. Technol. 2005, 197, 193-200. [CrossRef]

7. Diesselberg, M.; Stock, H.; Mayr, P. Corrosion protection of magnetron sputtered TiN coatings deposited on high strength aluminium alloys. Surf. Coat. Technol. 2004, 177, 399-403. [CrossRef]

8. Cheng, Y.; Pang, X.; Gao, K.; Yang, H.; Volinsky, A.A. Corrosion resistance and friction of sintered NdFeB coated with Ti/TiN multilayers. Thin Solid Film. 2014, 550, 428-434. [CrossRef]

9. Shi, J.R.; Ji, R.; Piramanayagam, S.N. Corrosion performance of thin hydrogenated amorphous carbon films prepared by magnetron sputtering. Diam. Relat. Mater. 2007, 16, 1716-1721. [CrossRef]

10. Cotrut, C.M.; Braic, V.; Balaceanu, M.; Titorencu, I.; Braic, M.; Parau, A.C. Corrosion resistance, mechanical properties and biocompatibility of Hf-containing ZrCN coatings. Thin Solid Film. 2013, 538, 48-55. [CrossRef]

11. Turcio-Ortega, D.; Rodil, S.; Muhl, S. Corrosion behavior of amorphous carbon deposit in $0.89 \% \mathrm{NaCl}$ by electrochemical impedance spectroscopy. Diam. Relat. Mater. 2009, 18, 1360-1368. [CrossRef] 
12. Wang, Q.; Zhou, F.; Zhou, Z.; Wang, C.; Zhang, W.; Li, L.K.Y.; Lee, S.-T. Effect of titanium or chromium content on the electrochemical properties of amorphous carbon coatings in simulated body fluid. Electrochim. Acta 2013, 112, 603-611. [CrossRef]

13. Joska, L.; Fojt, J.; Mestek, O.; Cvrcek, L.; Brezina, V. The effect of a DLC coating adhesion layer on the corrosion behavior of titanium and the Ti6Al4V alloy for dental implants. Surf. Coat. Technol. 2012, 206, 4899-4906. [CrossRef]

14. Madan, R.; Prakash, S. Modern Inorganic Chemistry; S. Chand: New Delhi, India, 1987.

15. Edgar, J.H.; Du, L.; Nyakiti, L.; Chaudhuri, J. Native oxide and hydroxides and their implications for bulk AlN crystal growth. J. Cryst. Growth 2008, 310, 4002-4006. [CrossRef]

16. Reitz, W. Corrosion and corrosion protection handbook. Mater. Manuf. Process 1993, 8, 269-270. [CrossRef]

17. Gao, S.; Dong, C.; Luo, H.; Xiao, K.; Pan, X.; Li, X. Scanning electrochemical microscopy study on the electrochemical behavior of $\mathrm{CrN}$ film formed on 304 stainless steel by magnetron sputtering. Electrochim. Acta 2013, 114, 233-241. [CrossRef]

18. Saha, N.C.; Tompkins, H.G. Titanium nitride oxidation chemistry: An X-ray photoelectron spectroscopy study. J. Appl. Phys. 1992, 72, 3072-3079. [CrossRef]

19. Roman, D.; Bernardi, J.; de Amorim, C.L.; de Souza, F.S.; Spinelli, A.; Giacomelli, C.; Figueroa, C.A.; Baumvol, I.J.; Basso, R.L. Effect of deposition temperature on microstructure and corrosion resistance of $\mathrm{ZrN}$ thin films deposited by DC reactive magnetron sputtering. Mater. Chem. Phys. 2011, 130, 147-153. [CrossRef]

20. Fenker, M.; Balzer, M.; Büchi, R.; Jehn, H.; Kappl, H.; Lee, J.J. Deposition of NbN thin films onto high-speed steel using reactive magnetron sputtering for corrosion protective applications. Surf. Coat. Technol. 2003, 163, 169-175. [CrossRef]

21. Pedrosa, P.; Alves, E.; Barradas, N.; Fiedler, P.; Haueisen, J.; Vaz, F.; Fonseca, C. $\mathrm{TiN}_{x}$ coated polycarbonate for bio-electrode applications. Corros. Sci. 2012, 56, 49-57. [CrossRef]

22. Dimitrova, V.; Manova, D.; Djulgerova, R. Element composition and electrochemical behaviour of polycrystalline AlN thin films. Surf. Coat. Technol. 2000, 123, 12-16. [CrossRef]

23. Liu, C.; Bi, Q.; Ziegele, H.; Leyland, A.; Matthews, A. Structure and corrosion properties of PVD Cr-N coatings. J. Vac. Sci. Technol. A 2002, 20, 772-780. [CrossRef]

24. Rocha, L.; Ariza, E.; Ferreira, J.; Vaz, F.; Ribeiro, E.; Rebouta, L.; Alves, E.; Ramos, A.; Goudeau, P.; Riviere, J. Structural and corrosion behaviour of stoichiometric and substoichiometric TiN thin films. Surf. Coat. Technol. 2004, 180, 158-163. [CrossRef]

25. Ariza, E.; Rocha, L.; Vaz, F.; Rebouta, L.; Ferreira, J.; Alves, E.; Goudeau, P.; Rivière, J. Corrosion Behaviour of Substoichiometric TiN $N_{x}$ Films Produced by DC Magnetron Sputtering; Trans Tech Publications: Zürich, Switzerland, 2003.

26. Cunha, L.T.; Pedrosa, P.; Tavares, C.J.; Alves, E.; Vaz, F.; Fonseca, C. The role of composition, morphology and crystalline structure in the electrochemical behaviour of $\mathrm{TiN}_{x}$ thin films for dry electrode sensor materials. Electrochim. Acta 2009, 55, 59-67. [CrossRef]

27. Ananthakumar, R.; Subramanian, B.; Kobayashi, A.; Jayachandran, M. Electrochemical corrosion and materials properties of reactively sputtered TiN/TiAlN multilayer coatings. Ceram. Int. 2012, 38, 477-485. [CrossRef]

28. Cunha, L.; Andritschky, M.; Rebouta, L.; Silva, R. Corrosion of TiN,(TiAl) N and CrN hard coatings produced by magnetron sputtering. Thin Solid Film. 1998, 317, 351-355. [CrossRef]

29. Grips, V.W.; Barshilia, H.C.; Selvi, V.E.; Rajam, K. Electrochemical behavior of single layer CrN, TiN, TiAlN coatings and nanolayered TiAlN/CrN multilayer coatings prepared by reactive direct current magnetron sputtering. Thin Solid Film. 2006, 514, 204-211. [CrossRef]

30. Fenker, M.; Balzer, M.; Kappl, H. Corrosion behaviour of decorative and wear resistant coatings on steel deposited by reactive magnetron sputtering-Tests and improvements. Thin Solid Film. 2006, 515, 27-32. [CrossRef]

31. Zhang, Z.; Rapaud, O.; Bonasso, N.; Mercs, D.; Dong, C.; Coddet, C. Microstructures and corrosion behaviors of $\mathrm{Zr}$ modified CrN coatings deposited by DC magnetron sputtering. Vacuum 2008, 82, 1332-1336. [CrossRef]

32. Kertzman, Z.; Marchal, J.; Suarez, M.; Staia, M.H.; Filip, P.; Kohli, P.; Aouadi, S.M. Mechanical, tribological, and biocompatibility properties of $\mathrm{ZrN}-\mathrm{Ag}$ nanocomposite films. J. Biomed. Mater. Res. Part A 2008, 84, 1061-1067. [CrossRef] 
33. Pedrosa, P.; Alves, E.; Barradas, N.P.; Martin, N.; Fiedler, P.; Haueisen, J.; Vaz, F.; Fonseca, C. Electrochemical behaviour of nanocomposite Agx: TiN thin films for dry biopotential electrodes. Electrochim. Acta 2014, 125, 48-57. [CrossRef]

34. Alves, V.A.; Brett, C.; Cavaleiro, A. Electrochemical corrosion of magnetron sputtered WTiN-coated mild steels in a chloride medium. Surf. Coat. Technol. 2002, 161, 257-266. [CrossRef]

35. Sanchéz, J.; Sanchéz, O.; Ipaz, L.; Aperador, W.; Caicedo, J.; Amaya, C.; Landaverde, M.; Beltran, F.E.; Muñoz-Saldaña, J.; Zambrano, G. Mechanical, tribological, and electrochemical behavior of $\mathrm{Cr}_{1-x} \mathrm{Al}_{x} \mathrm{~N}$ coatings deposited by rf reactive magnetron co-sputtering method. Appl. Surf. Sci. 2010, 256, 2380-2387. [CrossRef]

36. Calderon, V.S.; Cavaleiro, A.; Carvalho, S. Electrochemical response of $\mathrm{ZrCN}-\mathrm{Ag}-\mathrm{a}(\mathrm{C}, \mathrm{N})$ coatings in simulated body fluids. Electrochim. Acta 2015, 176, 898-906. [CrossRef]

37. Calderon, V.S.; Lopez, V.; Alves, C.F.A.; Cavaleiro, A.; Carvalho, S. Structural and electrochemical characterization of $\mathrm{Zr}-\mathrm{C}-\mathrm{N}-\mathrm{Ag}$ coatings deposited by DC dual magnetron sputtering. Corros. Sci. 2014, 80, 229-236. [CrossRef]

38. Cui, X.; Jin, G.; Hao, J.; Li, J.; Guo, T. The influences of Si content on biocompatibility and corrosion resistance of Zr-Si-N films. Surf. Coat. Technol. 2013, 228, S524-S528. [CrossRef]

39. Selvi, V.E.; Grips, V.K.W.; Barshilia, H.C. Electrochemical behavior of superhard nanocomposite coatings of $\mathrm{TiN} / \mathrm{Si}_{3} \mathrm{~N}_{4}$ prepared by reactive DC unbalanced magnetron sputtering. Surf. Coat. Technol. 2013, 224, 42-48. [CrossRef]

40. Kuptsov, K.; Kiryukhantsev-Korneev, P.V.; Sheveyko, A.; Shtansky, D. Comparative study of electrochemical and impact wear behavior of TiCN, TiSiCN, TiCrSiCN, and TiAlSiCN coatings. Surf. Coat. Technol. 2013, 216, 273-281. [CrossRef]

41. Byon, E.; Son, M.; Hara, N.; Sugimoto, K. Corrosion behavior of boron-carbon-nitride films grown by magnetron sputtering. Thin Solid Film. 2004, 448, 197-200. [CrossRef]

42. Calderon, S.; Ferreri, I.; Henriques, M.; de Hosson, J.T.M.; Cavaleiro, A.; Carvalho, S. Nano-galvanic coupling for enhanced $\mathrm{Ag}^{+}$release in $\mathrm{ZrCN}-\mathrm{Ag}$ films: Antibacterial application. Surf. Coat. Technol. 2016, 298, 1-6. [CrossRef]

43. Jacob, W.; Möller, W. On the structure of thin hydrocarbon films. Appl. Phys. Lett. 1993, 63, 1771-1773. [CrossRef]

44. Khun, N.; Liu, E.; Yang, G. Structure, scratch resistance and corrosion performance of nickel doped diamond-like carbon thin films. Surf. Coat. Technol. 2010, 204, 3125-3130. [CrossRef]

45. Khun, N.; Liu, E. Influence of carbon sputtering power on structure, corrosion resistance, adhesion strength and wear resistance of platinum/ruthenium/nitrogen doped diamond-like carbon thin films. Surf. Coat. Technol. 2010, 205, 853-860. [CrossRef]

46. Lu, Z.; Chung, C. Electrochemical characterization of diamond like carbon thin films. Diam. Relat. Mater. 2008, 17, 1871-1876. [CrossRef]

47. Manninen, N.K.; Alves, C.A.; Carvalho, S.; Cavaleiro, A. Influence of hydrogen incorporation and coating thickness on the corrosion resistance of carbon based coatings deposited by magnetron sputtering. Surf. Coat. Technol. 2015, 275, 127-132. [CrossRef]

48. Reisel, G.; Irmer, G.; Wielage, B.; Dorner-Reisel, A. Electrochemical corrosion behavior of carbon-based thin films in chloride ions containing electrolytes. Thin Solid Film. 2006, 515, 1038-1042. [CrossRef]

49. Oliveira, M.; Vieira, A.; Massi, M. Electrochemical behavior of the Ti-6Al-4V alloy coated with aC:H films. Diam. Relat. Mater. 2003, 12, 2136-2146. [CrossRef]

50. Högström, J.; Andersson, M.; Jansson, U.; Björefors, F.; Nyholm, L. On the evaluation of corrosion resistances of amorphous chromium-carbon thin-films. Electrochim. Acta 2014, 122, 224-233. [CrossRef]

51. Dhandapani, V.S.; Thangavel, E.; Arumugam, M.; Shin, K.S.; Veeraraghavan, V.; Yau, S.Y.; Kim, C.; Kim, D.-e. Effect of Ag content on the microstructure, tribological and corrosion properties of amorphous carbon coatings on 316L SS. Surf. Coat. Technol. 2014, 240, 128-136. [CrossRef]

52. Hong, C.; Tu, J.; Liu, D.; Li, R.; Gu, C. The electrochemical and mechanical properties of Ti incorporated amorphous carbon films in Hanks' solution. Appl. Surf. Sci. 2010, 256, 4859-4866. [CrossRef]

53. Liu, D.; Tu, J.; Chen, R.; Gu, C. Microstructure, corrosion resistance and biocompatibility of titanium incorporated amorphous carbon nitride films. Surf. Coat. Technol. 2011, 206, 165-171. [CrossRef] 
54. Masami, I.; Setsuo, N.; Tsutomu, S.; Junho, C. Improvement of corrosion protection property of Mg-alloy by DLC and Si-DLC coatings with PBII technique and multi-target DC-RF magnetron sputtering. Nucl. Instrum. Methods Phys. Res. Sect. B Beam Interact. Mater. At. 2009, 267, 1675-1679. [CrossRef]

55. Khun, N.; Liu, E. Enhancement of adhesion strength and corrosion resistance of nitrogen or platinum/ruthenium/nitrogen doped diamond-like carbon thin films by platinum/ruthenium underlayer. Diam. Relat. Mater. 2010, 19, 1065-1072. [CrossRef]

56. Guruz, M.U.; Dravid, V.P.; Chung, Y.W.; Lacerda, M.M.; Bhatia, C.S.; Yu, Y.H.; Lee, S.C. Corrosion performance of ultrathin carbon nitride overcoats synthesized by magnetron sputtering. Thin Solid Film. 2001, 381, 6-9. [CrossRef]

57. Khun, N.; Liu, E. Investigation of corrosion behavior of nitrogen doped and platinum/ruthenium doped diamond-like carbon thin films in Hank's solution. Mater. Sci. Eng. C 2011, 31, 1539-1544. [CrossRef]

58. Thornton, J.A. Structure-Zone Models Of Thin Films. Model. Opt. Thin Film. 1988, 821, 95-105.

59. Messier, R.; Giri, A.P.; Roy, R.A. Revised structure zone model for thin film physical structure. J. Vac. Sci. Technol. A 1984, 2, 500-503. [CrossRef]

60. Liu, C.; Bi, Q.; Leyland, A.; Matthews, A. An electrochemical impedance spectroscopy study of the corrosion behaviour of PVD coated steels in $0.5 \mathrm{~N} \mathrm{NaCl}$ aqueous solution: Part II.: EIS interpretation of corrosion behaviour. Corros. Sci. 2003, 45, 1257-1273. [CrossRef]

61. Madaoui, N.; Saoula, N.; Zaid, B.; Saidi, D.; Ahmed, A.S. Structural, mechanical and electrochemical comparison of TiN and TiCN coatings on XC48 steel substrates in $\mathrm{NaCl} 3.5 \%$ water solution. Appl. Surf. Sci. 2014, 312, 134-138. [CrossRef]

62. Ruden, A.; Restrepo-Parra, E.; Paladines, A.; Sequeda, F. Corrosion resistance of CrN thin films produced by dc magnetron sputtering. Appl. Surf. Sci. 2013, 270, 150-156. [CrossRef]

63. Ahn, S.; Hong, J.; Kim, J.; Han, J. Effect of microstructure on corrosion behavior of TiN hard coatings produced by a modified two-grid attachment magnetron sputtering process. Thin Solid Film. 2007, 515, 6878-6883. [CrossRef]

64. Chipatecua, Y.L.; Olaya, J.J.; Arias, D.F. Corrosion behaviour of CrN/Cr multilayers on stainless steel deposited by unbalanced magnetron sputtering. Vacuum 2012, 86, 1393-1401. [CrossRef]

65. Lin, C.H.; Duh, J.G. Corrosion behavior of (Ti-Al-Cr-Si-V) $\mathrm{N}_{y}$ coatings on mild steels derived from RF magnetron sputtering. Surf. Coat. Technol. 2008, 203, 558-561. [CrossRef]

66. Grips, V.; Selvi, V.E.; Barshilia, H.C.; Rajam, K. Effect of electroless nickel interlayer on the electrochemical behavior of single layer $\mathrm{CrN}$, TiN, TiAlN coatings and nanolayered TiAlN/CrN multilayer coatings prepared by reactive dc magnetron sputtering. Electrochim. Acta 2006, 51, 3461-3468. [CrossRef]

67. Elsener, B.; Rota, A.; Böhni, H. Impedance study on the corrosion of PVD and CVD titanium nitride coatings. Mater. Sci. Forum 1991, 44, 29-38. [CrossRef]

68. Vetter, J.; Stüber, M.; Ulrich, S. Growth effects in carbon coatings deposited by magnetron sputtering. Surf. Coat. Technol. 2003, 168, 169-178. [CrossRef]

69. Subramanian, B.; Swaminathan, V.; Jayachandran, M. Microstructural, tribological and electrochemical corrosion studies on reactive DC magnetron sputtered zirconium nitride films with Zr interlayer on steel. Met. Mater. Int. 2012, 18, 957-964. [CrossRef]

70. He, C.; Zhang, J.; Wang, J.; Ma, G.; Zhao, D.; Cai, Q. Effect of structural defects on corrosion initiation of TiN nanocrystalline films. Appl. Surf. Sci. 2013, 276, 667-671. [CrossRef]

71. Flores, M.; Huerta, L.; Escamilla, R.; Andrade, E.; Muhl, S. Effect of substrate bias voltage on corrosion of TiN/Ti multilayers deposited by magnetron sputtering. Appl. Surf. Sci. 2007, 253, 7192-7196. [CrossRef]

72. Barshilia, H.C.; Prakash, M.S.; Poojari, A.; Rajam, K. Corrosion behavior of nanolayered TiN/NbN multilayer coatings prepared by reactive direct current magnetron sputtering process. Thin Solid Film. 2004, 460, 133-142. [CrossRef]

73. Caicedo, J.; Amaya, C.; Cabrera, G.; Esteve, J.; Aperador, W.; Gómez, M.; Prieto, P. Corrosion surface protection by using titanium carbon nitride/titanium-niobium carbon nitride multilayered system. Thin Solid Film. 2011, 519, 6362-6368. [CrossRef]

74. Ordine, A.; Achete, C.; Mattos, O.; Margarit, I.; Camargo, S., Jr.; Hirsch, T. Magnetron sputtered SiC coatings as corrosion protection barriers for steels. Surf. Coat. Technol. 2000, 133, 583-588. [CrossRef] 
75. Reinhard, C.; Ehiasarian, A.P.; Hovsepian, P.E. CrN/NbN superlattice structured coatings with enhanced corrosion resistance achieved by high power impulse magnetron sputtering interface pre-treatment. Thin Solid Film. 2007, 515, 3685-3692. [CrossRef]

76. Vacandio, F.; Massiani, Y.; Gergaud, P.; Thomas, O. Stress, porosity measurements and corrosion behaviour of AlN films deposited on steel substrates. Thin Solid Film. 2000, 359, 221-227. [CrossRef]

77. Zhu, S.; Chen, L.; Wu, Y.; Hu, Y.; Liu, T.; Tang, K.; Wei, Q. Microstructure and corrosion resistance of $\mathrm{Cr} / \mathrm{Cr}_{2} \mathrm{~N}$ multilayer film deposited on the surface of depleted uranium. Corros. Sci. 2014, 82, 420-425. [CrossRef]

78. Beliardouh, N.; Bouzid, K.; Nouveau, C.; Tlili, B.; Walock, M. Tribological and electrochemical performances of $\mathrm{Cr} / \mathrm{CrN}$ and $\mathrm{Cr} / \mathrm{CrN} / \mathrm{CrAlN}$ multilayer coatings deposited by RF magnetron sputtering. Tribol. Int. 2014, 82, 443-452. [CrossRef]

79. Disegi, J.; Eschbach, L. Stainless steel in bone surgery. Injury 2000, 31, D2-D6. [CrossRef]

80. Plecko, M.; Sievert, C.; Andermatt, D.; Frigg, R.; Kronen, P.; Klein, K.; Stübinger, S.; Nuss, K.; Bürki, A.; Ferguson, S. Osseointegration and biocompatibility of different metal implants-A comparative experimental investigation in sheep. BMC Musculoskelet. Disord. 2012, 13, 1471-1483. [CrossRef]

81. Kumar, A.; Kaur, D. Nanoindentation and corrosion studies of TiN/NiTi thin films for biomedical applications. Surf. Coat. Technol. 2009, 204, 1132-1136. [CrossRef]

82. Oliveira, M.; Pereira, L.; Cairo, C. Porous structure characterization in titanium coating for surgical implants. Mater. Res. 2002, 5, 269-273. [CrossRef]

83. Pohler, O.E. Unalloyed titanium for implants in bone surgery. Injury 2000, 31, D7-D13. [CrossRef]

84. Disegi, J. Titanium alloys for fracture fixation implants. Injury 2000, 31, D14-D17. [CrossRef]

85. Ye, X.; Wang, L.; Tse, Z.T.H.; Tang, G.; Song, G. Effects of high-energy electro-pulsing treatment on microstructure, mechanical properties and corrosion behavior of Ti-6Al-4V alloy. Mater. Sci. Eng. C 2015, 49, 851-860. [CrossRef] [PubMed]

86. Ye, X.; Yang, Y.; Tang, G. Microhardness and corrosion behavior of surface gradient oxide coating on the titanium alloy strips under high energy electro-pulsing treatment. Surf. Coat. Technol. 2014, 258, 467-484. [CrossRef]

87. Calderon, V.S.; Galindo, R.E.; Oliveira, J.; Cavaleiro, A.; Carvalho, S. Ag ${ }^{+}$release and corrosion behavior of zirconium carbonitride coatings with silver nanoparticles for biomedical devices. Surf. Coat. Technol. 2013, 222, 104-111. [CrossRef]

88. Balaceanu, M.; Petreus, T.; Braic, V.; Zoita, C.; Vladescu, A.; Cotrutz, C.; Braic, M. Characterization of Zr-based hard coatings for medical implant applications. Surf. Coat. Technol. 2010, 204, 2046-2050. [CrossRef]

89. De-Melo, J.F.; Gjerdet, N.R.; Erichsen, E.S. Metal release from cobalt-chromium partial dentures in the mouth. Acta Odontol. Scand. 1983, 41, 71-74. [CrossRef] [PubMed]

90. Hanawa, T. Metal ion release from metal implants. Mater. Sci. Eng. C 2004, 24, 745-752. [CrossRef]

91. Gazia, R.; Mandracci, P.; Mussano, F.; Carossa, S. AlN $\mathrm{Al}_{x}$ and $\mathrm{a}-\mathrm{SiO}_{x}$ coatings with corrosion resistance properties for dental implants. Surf. Coat. Technol. 2011, 206, 1109-1115. [CrossRef]

92. Subramanian, B.; Ananthakumar, R.; Jayachandran, M. Microstructural, mechanical and electrochemical corrosion properties of sputtered titanium-aluminum-nitride films for bio-implants. Vacuum 2010, 85, 601-609. [CrossRef]

93. Sunderman, F.W. A review of the carcinogenicities of nickel, chromium and arsenic compounds in man and animals. Prev. Med. 1976, 5, 279-294. [CrossRef]

94. Ruiqiang, H.; Shengli, M.; Paul, C.K. Effects of diamond-like carbon coatings with different thickness on mechanical properties and corrosion behavior of biomedical NiTi alloy. Rare Met. Mater. Eng. 2012, 41, 1505-1510. [CrossRef]

95. Rack, H.; Qazi, J. Titanium alloys for biomedical applications. Mater. Sci. Eng. C 2006, 26, 1269-1277. [CrossRef]

96. Yildiz, F.; Yetim, A.; Alsaran, A.; Efeoglu, I. Wear and corrosion behaviour of various surface treated medical grade titanium alloy in bio-simulated environment. Wear 2009, 267, 695-701. [CrossRef]

97. Kasemo, B. Biocompatibility of titanium implants: Surface science aspects. J. Prosthet. Dent. 1983, 49, 832-837. [CrossRef]

98. Pouilleau, J.; Devilliers, D.; Garrido, F.; Durand-Vidal, S.; Mahé, E. Structure and composition of passive titanium oxide films. Mater. Sci. Eng. B 1997, 47, 235-243. [CrossRef] 
99. Franchi, M.; Bacchelli, B.; Martini, D.; de Pasquale, V.; Orsini, E.; Ottani, V.; Fini, M.; Giavaresi, G.; Giardino, R.; Ruggeri, A. Early detachment of titanium particles from various different surfaces of endosseous dental implants. Biomaterials 2004, 25, 2239-2246. [CrossRef]

100. Kim, W.G.; Choe, H.C. Effects of TiN coating on the corrosion of nanostructured Ti-30Ta- $x \mathrm{Zr}$ alloys for dental implants. Appl. Surf. Sci. 2012, 258, 1929-1934. [CrossRef]

101. Krishnan, V.; Krishnan, A.; Remya, R.; Ravikumar, K.; Nair, S.A.; Shibli, S.; Varma, H.; Sukumaran, K.; Kumar, K.J. Development and evaluation of two PVD-coated $\beta$-titanium orthodontic archwires for fluoride-induced corrosion protection. Acta Biomater. 2011, 7, 1913-1927. [CrossRef]

102. Roman, D.; Bernardi, J.C.; Boeira, C.D.; de Souza, F.S.; Spinelli, A.; Figueroa, C.A.; Basso, R.L. Nanomechanical and electrochemical properties of $\mathrm{ZrN}$ coated NiTi shape memory alloy. Surf. Coat. Technol. 2012, 206, 4645-4650. [CrossRef]

103. Marulanda, D.; Olaya, J.; Piratoba, U.; Mariño, A.; Camps, E. The effect of bilayer period and degree of unbalancing on magnetron sputtered $\mathrm{Cr} / \mathrm{CrN}$ nano-multilayer wear and corrosion. Thin Solid Film. 2011, 519, 1886-1893. [CrossRef]

104. Calderon Velasco, S.; Cavaleiro, A.; Carvalho, S. Functional properties of ceramic-Ag nanocomposite coatings produced by magnetron sputtering. Prog. Mater. Sci. 2016, 84, 158-191. [CrossRef]

105. Kumar, A.; Singh, D.; Goyal, R.N.; Kaur, D. Fabrication and nanoindentation properties of TiN/NiTi thin films and their applications in electrochemical sensing. Talanta 2009, 78, 964-969. [CrossRef] [PubMed]

106. Shanaghi, A.; Chu, P.K.; Rouhaghdam, A.R.S.; Xu, R.; Hu, T. Structure and corrosion resistance of $\mathrm{Ti} / \mathrm{TiC}$ coatings fabricated by plasma immersion ion implantation and deposition on nickel-titanium. Surf. Coat. Technol. 2013, 229, 151-155. [CrossRef]

107. Alemón, B.; Flores, M.; Canto, C.; Andrade, E.; de Lucio, O.; Rocha, M.; Broitman, E. Ion beam analysis, corrosion resistance and nanomechanical properties of TiAlCN/CN $\mathrm{CN}_{x}$ multilayer grown by reactive magnetron sputtering. Nucl. Instrum. Methods Phys. Res. Sect. B Beam Interact. Mater. At. 2014, 331, 134-139. [CrossRef]

108. Williams, D. Essential Biomaterials Science; Cambridge University Press: Cambridge, UK, 2014.

109. Ruiqiang, H.; Ma, S.; Chu, P.K. Corrosion behavior of DLC-coated NiTi alloy in the presence of serum proteins. Diam. Relat. Mater. 2010, 19, 1230-1234.

110. Hauert, R.; Falub, C.; Thorwarth, G.; Thorwarth, K.; Affolter, C.; Stiefel, M.; Podleska, L.; Taeger, G. Retrospective lifetime estimation of failed and explanted diamond-like carbon coated hip joint balls. Acta Biomater. 2012, 8, 3170-3176. [CrossRef]

111. Love, C.A.; Cook, R.B.; Harvey, T.J.; Dearnley, P.A.; Wood, R.J.K. Diamond like carbon coatings for potential application in biological implants-A review. Tribol. Int. 2013, 63, 141-150. [CrossRef]

112. Van Hove, R.P.; Sierevelt, I.N.; van Royen, B.J.; Nolte, P.A. Titanium-nitride coating of orthopaedic implants: A review of the literature. BioMed Res. Int. 2015, 2015, 485975. [CrossRef]

113. Buechel, F.F.; Pappas, M.J. A metal/ultrahigh-molecular-weight polyethylene cementless surface replacement. Semin. Arthroplast. 2011, 22, 66-74. [CrossRef]

114. Van Hove, R.P.; Brohet, R.M.; van Royen, B.J.; Nolte, P.A. No clinical benefit of titanium nitride coating in cementless mobile-bearing total knee arthroplasty. Knee Surg. Sports Traumatol. Arthrosc. 2015, 23, 1833-1840. [CrossRef] [PubMed]

115. Buechel, F.F.; Pappas, M.J. Ten-year evaluation of cementless Buechel-Pappas meniscal bearing total ankle replacement. Foot Ankle Int. 2003, 24, 462-472. [CrossRef] [PubMed]

116. Buechel, F.; Pappas, M. Survivorship and clinical evaluation of cementless, meniscal-bearing total ankle replacements. Semin. Arthroplast. 1992, 3, 43-50.

117. Mohammed, A.; Metcalfe, A.; Woodnutt, D. Medium-term outcome of titanium nitride, mobile bearing total knee replacement. Acta Orthop. Belg. 2014, 80, 269-275.

118. Raimondi, M.T.; Pietrabissa, R. The in-vivo wear performance of prosthetic femoral heads with titanium nitride coating. Biomaterials 2000, 21, 907-913. [CrossRef]

119. Harman, M.K.; Banks, S.A.; Hodge, W.A. Wear analysis of a retrieved hip implant with titanium nitride coating. J. Arthroplast. 1997, 12, 938-945. [CrossRef]

120. Łapaj, Ł.; Wendland, J.; Markuszewski, J.; Mróz, A.; Wiśniewski, T. Retrieval analysis of titanium nitride (TiN) coated prosthetic femoral heads articulating with polyethylene. J. Mech. Behav. Biomed. Mater. 2015, 55, 127-139. [CrossRef] 
121. Taeger, G.; Podleska, L.; Schmidt, B.; Ziegler, M.; Nast-Kolb, D. Comparison of diamond-like-carbon and alumina-oxide articulating with polyethylene in total hip arthroplasty. Mater. Werkst. 2003, 34, 1094-1100. [CrossRef]

122. Hauert, R.; Thorwarth, K.; Thorwarth, G. An overview on diamond-like carbon coatings in medical applications. Surf. Coat. Technol. 2013, 233, 119-130. [CrossRef]

123. Joyce, T. Examination of failed ex vivo metal-on-metal metatarsophalangeal prosthesis and comparison with theoretically determined lubrication regimes. Wear 2007, 263, 1050-1054. [CrossRef]

124. Hauert, R.; Thorwarth, G.; Müller, U.; Stiefel, M.; Falub, C.; Thorwarth, K.; Joyce, T. Analysis of the in-vivo failure of the adhesive interlayer for a DLC coated articulating metatarsophalangeal joint. Diam. Relat. Mater. 2012, 25, 34-39. [CrossRef]

125. Komotori, J.; Lee, B.; Dong, H.; Dearnley, P. Corrosion response of surface engineered titanium alloys damaged by prior abrasion. Wear 2001, 251, 1239-1249. [CrossRef]

126. Falub, C.V.; Thorwarth, G.; Affolter, C.; Müller, U.; Voisard, C.; Hauert, R. A quantitative in vitro method to predict the adhesion lifetime of diamond-like carbon thin films on biomedical implants. Acta Biomater. 2009, 5, 3086-3097. [CrossRef] [PubMed]

127. Liu, C.; Hu, D.; Xu, J.; Yang, D.; Qi, M. In vitro electrochemical corrosion behavior of functionally graded diamond-like carbon coatings on biomedical nitinol alloy. Thin Solid Film. 2006, 496, 457-462. [CrossRef]

128. Fenker, M.; Balzer, M.; Jehn, H.; Kappl, H.; Lee, J.J.; Lee, K.H.; Park, H.S. Improvement of the corrosion resistance of hard wear resistant coatings by intermediate plasma etching or multilayered structure. Surf. Coat. Technol. 2002, 150, 101-106. [CrossRef]

129. Bertrand, G.; Mahdjoub, H.; Meunier, C. A study of the corrosion behaviour and protective quality of sputtered chromium nitride coatings. Surf. Coat. Technol. 2000, 126, 199-209. [CrossRef]

130. Caicedo, J.C.; Zambrano, G.; Aperador, W.; Escobar-Alarcon, L.; Camps, E. Mechanical and electrochemical characterization of vanadium nitride (VN) thin films. Appl. Surf. Sci. 2011, 258, 312-320. [CrossRef]

(C) 2019 by the authors. Licensee MDPI, Basel, Switzerland. This article is an open access article distributed under the terms and conditions of the Creative Commons Attribution (CC BY) license (http://creativecommons.org/licenses/by/4.0/). 